\title{
Shipping to Heterogeneous Customers with Competing Carriers
}

\author{
Tao Lu* Ying-Ju Chen ${ }^{\dagger} \quad$ Jan C. Fransoo ${ }^{\ddagger}$ Chung-Yee Lee ${ }^{\S}$
}

November 29, 2018

\begin{abstract}
Problem definition: We consider a shipper transporting and selling a short-life-cycle product to a destination market. Customers in the destination market obtain higher utility if they receive the product earlier but their time preferences are heterogeneous. Two transportation service providers (i.e., carriers) offer distinct speeds and competing freight rates. This study analyzes the shipper's optimal shipping strategy under carrier competition. Academic/Practical relevance: Perishable products are commonly shipped via multiple means of transport. The faster the mode of transport is, the more expensive it is, but speed enables the product to reach the market with higher quality. In addition to the trade-off between speed and cost, the competition between carriers can also influence the shipper's transportation procurement strategies. Our model highlights the implications of carrier competition in a dual sourcing problem. Methodology: We study a two-stage game-theoretical framework: Carriers first compete on freight rates, and then the shipper determines the shipping schedule. Results: The shipper may benefit from product differentiation via dual-mode shipping, in which the shipment that arrives earlier is sold at a premium price. In equilibrium, the shipper's profit can be U-shaped in the speed difference between carriers. Dual sourcing may be inferior to simply restricting a single shipping service in a winner-take-all fashion. Managerial implications: This study reveals an underlying trade-off between the operational advantage from product differentiation and the cost advantage from carrier competition. To benefit from either of these advantages, a shipper should use two carriers with either very distinct or very similar speeds. Single sourcing may bring an additional cost advantage that outweighs the value of production differentiation through dual sourcing.
\end{abstract}

Key words: transport procurement, competition, product differentiation, dual sourcing.

\footnotetext{
*Rotterdam School of Management, Erasmus University, The Netherlands

${ }^{\dagger}$ HKUST Business School and School of Engineering, Hong Kong University of Science and Technology, Hong Kong

${ }^{\ddagger}$ Kühne Logistics University, Germany

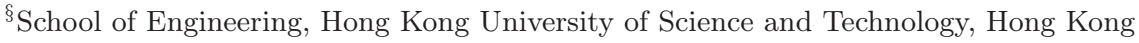




\section{Introduction}

In the contemporary logistics market, merchandise is transported via multiple modes, including air, road, rail and sea. Mangoes are imported from Brazil, Peru, and other non-European countries to the European Union (EU) both by air and by ocean (Sangho et al., 2011; Araújo and Garcia, 2016), for a total volume of 300,000 tons that in 2015 was worth upwards of 522 million Euros (CBI, 2016). Scandinavian seafood is exported by air, road and ocean (Larsen, 2003). Seafood exports from Norway alone achieved 10.59 billion US Dollars in 2016 (Reuters, 2017). Kenyan flowers imported to the Netherlands have recently been delivered with a combination of ocean and air transport (Hortiwise, 2013).

One of the main reasons for the use of mixed transportation modes is to cater to customers' divergent preferences for product quality. Araújo and Garcia (2016, p. 292) reported that the dominant view of their respondents is that there are well defined segments in the EU mango market, the largest of which is comprised of "consumers of average purchasing power, who buy the sea-freighted mangoes,", while another segment is made up of "consumers of the air-freighted mangoes," which sell for almost three times as much as manoges transported by ship ${ }^{1}$ The faster transportation makes the product available in the market at a higher quality but also incurs a higher shipping cost. As noted in Sangho et al. (2011, p. 14-18), air freighting allows Malian mangoes to be picked at a more advanced stage of maturity; this translates in an export of sweeter products but at a significantly higher cost $;^{2}$ shipping mangoes via sea freight instead of only air, in contrast, enables Malians to export in higher volumes and reach broader markets as sea freighted mangoes are more cost competitive. Therefore, from the perspective of fruit exporters, choosing the means of transport is critically important, given the cost differences between fast and slow transport modes.

Likewise, in seafood supply chains, sea freight is primarily used for frozen fish whereas road or air transport is used mainly to deliver fresh or chilled fish (Larsen, 2003). ${ }^{3}$ Customers (e.g., restaurants) consider fresh and frozen fish as vertically different products, i.e., fresh fish is generally preferred if fresh and frozen fish sell at the same price ${ }^{4}$ fine dining restaurants are generally more demanding of freshness than fast-food restaurants. In addition, according to our communications with a Dutch flower company, only a limited portion of flowers is currently

\footnotetext{
${ }^{1}$ The distribution channels for the low-end segment includes, for instance, discount markets and neighborhood greengrocers, whereas the channels for the high-end segment include upscale retailers, restaurants, and gourmet fruit stores (Araújo and Garcia, 2016; Sangho et al., 2011).

${ }^{2}$ Exporters from Peru emphasized the high return of air-freighted mangoes as $200 \%$ higher than maritime shipments (Passion Fresh, 2013).

${ }^{3}$ Examples of seafood exporters selling the product in both frozen and fresh states can be found at http: //www.vsv.is/en/products-and-marketing/cod and http://en.salva-mar.com/productos/.

${ }^{4}$ According to a New York Times article (Moskin, 2004), many sushi bars in Japan and elsewhere would use frozen fish when fresh fish is more expensive than what the market can bear.
} 
transported by ocean because upscale retailers still only accept air-freighted products.

In this paper, we study a company that, like the above examples, exports a perishable product from its origin and then sells it in a destination market. To transport the product to its destination, the company (referred to as shipper hereafter) may use multiple transportation service providers (referred to as carriers hereafter), each operating at different speeds and costs. Furthermore, to attract more payload, carriers competitively offer their freight rates to the shipper. We aim to answer the following questions: (i) When should a shipper use multiple shipping modes to serve a vertically differentiated market? (ii) When carrier competition plays a role, what are the implications for the shipper's and carriers' profits, and especially the shipper's sourcing strategies?

To investigate these questions, we analyze a two-stage game involving a perishable-product shipper, two competing carriers with different speeds, and a continuum of utility-maximizing customers with heterogeneous preferences for product quality. A faster transportation service enables the product to be supplied with higher quality. First, carriers simultaneously determine their freight rates. After receiving the carriers' quotations, the shipper announces two selling prices, respectively, for shipments delivered by the two carriers. Then, individual customers decide at which price they want to buy the product. For given freight rates, we derive the conditions under which the shipper should use a combination of shipping modes such that shipments via the fast carrier will be sold at a premium price to high-end customers, whereas shipments via the slow carrier will be used to satisfy customers that are less demanding of quality Next, we characterize the Nash equilibrium for when carriers competitively determine freight rates. Among other findings, we show that the shipper may be better off when the speed of the faster carrier decreases: a smaller speed difference between carriers intensifies competition and can thus reduce the shipper's transportation costs in equilibrium. We also find that the shipper's profit can display a U-shaped curve in the speed difference between the two carriers, suggesting that the shipper use carriers with either substantially different or very similar speeds to leverage an operational advantage from product differentiation or a cost advantage from carrier competition, respectively.

Moreover, we consider an alternative single sourcing strategy under which carriers are selected in a winner-take-all fashion. Contrary to conventional wisdom, we prove that restricting to a single carrier may make the shipper better off as compared to the dual sourcing strategy. Dualmode shipping permits product differentiation, whereas single sourcing may enable the shipper to intensify carrier competition and thus leverage more cost advantage when compared to dual sourcing. Our results suggest that managers assess the trade-off between the additional cost 
advantage from single sourcing and the operational advantage of product differentiation. As our numerical findings suggest, relative to product differentiation's operational advantage, the additional cost advantage from single sourcing is more attractive when the product has a lower production cost or a higher potential quality. Additionally, results from our model extensions help explain how this trade-off is influenced by the shape of the customer-type distribution and the presence of quantity discounts. In particular, we find that single sourcing becomes less attractive as customer types become more homogeneous, as a lower degree of heterogeneity in the market makes the carrier competition more intense under dual sourcing; in such cases, single souring may not add much additional cost advantage. Similarly, when carriers compete in quantity discounts, their competition becomes more intense in general such that single sourcing yields less additional value compared to our base model in which the two compete in linear rates.

The remainder of this paper is organized as follows. Section 2 reviews the related literature. Section 3 describes the model framework and Section 4 presents our results. We explore several model extensions in Section 5 and conclude the paper in Section 6.

\section{Literature Review}

Various aspects of transportation procurement have been studied. Lim et al. (2008) examined a transportation procurement problem in which the shipper allocates freight to ocean carriers on each route of its network. Sharypova et al. (2012) considered a hinterland supply chain in which containers are distributed from the deep sea terminal to multiple inland terminals by barge. Hoen et al. (2013) studied a shipper that determines the inland transport modes and selling prices for multiple products with consideration for carbon emission. Cheon et al. (2017) developed an analytical framework to study the impact of the predictability of port processing time on

shippers' decision-making. Lu et al. (2017) considered a newsvendor-type shipper transporting a seasonal product whose selling price in the destination market declines over time. They showed that a portfolio of shipping services can be used to mitigate uncertainties in both demand and service schedules. Our study differs from the above literature in that we consider freight rates as endogenous and explore the price competition between carriers.

Our work is relevant to the literature on procurement management that takes delivery time into consideration. Cachon and Zhang (2006) studied the buyer's mechanism design problem when capacity costs are the private information of suppliers. Cachon and Zhang (2007) examined the role of performance-based demand allocation in incentivizing suppliers to offer fast services. Bernstein and de Véricourt (2008) considered two suppliers that compete for multiple buyers' demand by offering service guarantees. These papers focus mainly on production lead times and 
model suppliers based on queueing frameworks. Another related study is Ha et al. (2003) in which the authors study the supplier competition in delivery frequency and price.

Because shipments can potentially be spread across the selling season in our model, the shipper in effect provides quality-differentiated products to a pool of potential buyers with heterogeneous willingness-to-pay. From this perspective, our paper is relevant to the literature on product differentiation (more specifically, vertical differentiation). Mussa and Rosen (1978) and Moorthy (1984) developed a seminal framework for studying product differentiation in which a monopolistic firm determines the quality levels and prices for a menu of products and customers select the products to maximize their utility. A few subsequent papers have incorporated supply/production side issues into this classical problem. For example, Desai et al. (2001) took the manufacturing configuration of products into consideration to explore the trade-off between manufacturing cost and sales revenue. Netessine and Taylor (2007) studied the impact of production technology on product quality differentiation based on an Economic Order Quantity framework. Chen et al. (2013) investigated a situation in which the manufacturer operates a co-product technology that simultaneously outputs quality-differentiated products. All of these papers focus primarily on a centralized decision-maker, whereas we consider a shipper relying on self-interested and competing carriers to supply quality-differentiated products. While product differentiation has been studied under decentralized supply chains (e.g., Villas-Boas, 1998; Lu et al., 2018), our problem differs from theirs in that the (transportation) costs of products are determined by competing service providers.

Our model features competition between differentiated carriers, and therefore may relate to economic literature on differentiated duopoly/oligopoly. Numerous papers study the price and/or quantity competition between horizontally differentiated firms (e.g., Singh and Vives, 1984; Correa-López, 2007). In particular, Tanaka (2001) studied a vertically differentiated duopoly involving two competing firms of high and low quality, respectively. Our model departs from Tanaka's (2001) in that the competing firms in our model are service providers who offer transportation services to a shipper, rather than making profits directly from the end market.

Finally, our paper relates to the supply chain management literature concerning dual-sourcing strategies in the presence of supplier competition. The tension between the operational benefit of dual sourcing and the effect of carrier competition revealed by our model is reminiscent of Babich et al. (2007) and Yang et al. (2012) in the supply disruption setting, and Calvo and Martínez-de Albéniz (2015) in the quick response context. In our shipping problem, however, a combination of shipping modes is used for product differentiation. 


\section{The Model}

We consider a shipper that sends a certain type of short-life-cycle product from the origin to the customers in an overseas market. As stated in the introduction, a shorter transportation time makes the product available in the market at a higher quality. We therefore model the quality as a decreasing function of transportation time, denoted by $q(t)$. For ease of exposition, we assume that the quality function takes a linear form $q(t)=a-t .{ }^{5}$ The intercept $a$ represents the maximum quality that can be potentially supplied to the market if the transportation time were zero, and it captures other inherit attributes of quality, such as species and brand. Because this paper focuses on the impact of transportation time on quality, we assume that $a$ is a given parameter identical for all transported products.

Customers in the destination market have heterogeneous preferences for quality. To model this heterogeneity, we assume a continuum of infinitesimal customers in the destination with the market size normalized to one. Customers maximize their utility when making their purchasing decisions. We use $\theta \in[0, \bar{\theta}]$ to represent a customer's marginal willingness to pay for quality. The gross utility of receiving a product with quality $q(t)$ is then given by $\theta q(t)$ for a customer with marginal willingness to pay $\theta$. Similar customer setups are used widely in the literature (e.g., Chen et al., 2013; Lee et al., 2015b). In the base model, we assume that $\theta$ is uniformly distributed within $[0, \bar{\theta}]$ where $\bar{\theta}$ is a given parameter measuring the highest possible valuation among customers. We refer to $\theta$ as the customer's type. The shipper cannot observe each individual customer's type but knows the distribution of $\theta$. The uniform distribution together with infinitesimal customers implicitly presumes that customers' potential purchasing quantities are identical. In practice, fruit is sold through different channels. Thus, our base model focuses on channels consisting of small-sized customers (e.g., neighborhood greengrocers, restaurants and specialized retail stores) whose order quantities are relatively small and not very different from each other. In Section 5.1, we relax the uniform assumption on $\theta$ such that different types of customers can demand distinct volumes.

For each unit of product, the shipper incurs a production cost denoted by $c_{p}$. We will refer to $c_{p}$ as the production cost throughout the paper with the understanding that it can represent the procurement cost if the product is purchased from local producers in the origin (e.g., mangoes purchased from fruit growers). The supply is assumed to be ample at the origin compared to the potential demand in the overseas market. The shipper owns the product at time of shipment

\footnotetext{
${ }^{5}$ In practice, the quality is influenced by transportation time in various ways. In the example of mango export, air transport leads to higher quality as compared to ocean shipping, because mangoes can be picked up at a better stage of maturity (Sangho et al., 2011, p. 14). In the case of seafood, the fast mode of transportation enables fish to arrive in the market without having to be frozen. The linear specification of $q(t)$ is not essential for the analysis, and our main results qualitatively hold as long as $q(t)$ is decreasing in $t$.
} 
and therefore incurs the inventory holding cost during transportation. The inventory holding cost for each unit of product and each unit of time is denoted by $h$.

Two transport service providers, which are referred to as carriers in what follows, are available from the origin to the destination. Carriers differ in transportation times. Let $\mathbf{t}=\left(t_{1}, t_{2}\right)$ where $t_{i}$ is the transportation time of carrier $i(i=1,2)$. Without loss of generality, we assume $0 \leq t_{1}<t_{2} \leq a$ throughout the paper. That is, carrier 1 operates a faster service than carrier 2. The $t_{i}$ 's are assumed to be deterministic. ${ }^{6}$ Carrier $i$ incurs an operating cost $c_{i}$ for shipping one unit of product. We allow for any nonnegative $c_{i}$ 's in the analysis, even though $c_{1}>c_{2}$ is more probable in practice since $t_{1}<t_{2}$. Due to different transportation times, the shipper can deliver the product with quality $q\left(t_{i}\right)=a-t_{i}$ via carrier $i$. Given customers' heterogeneous preferences, the shipper's problem is to determine the selling price of the product shipped by each transportation service, given the freight rates quoted by the two carriers. Let $p_{i}$ represent the selling price of the shipment via carrier $i$. Anticipating the shipper's decisions, carriers simultaneously determine their freight rates to be offered to the shipper in a competitive manner to maximize their own profits. We denote by $r_{i}$ the freight rate quoted by carrier $i$. Note that the $t_{i}$ 's are determined by the nature of transportation means and fixed service schedules. Thus, we consider a game in which carriers compete in the $r_{i}$ 's while the $t_{i}$ 's are given.

The sequence of events is summarized as follows. (1) Carriers decide on the freight rates to be offered to the shipper. (2) Given freight rates $\mathbf{r}=\left(r_{1}, r_{2}\right)$ and corresponding transportation times $\mathbf{t}=\left(t_{1}, t_{2}\right)$, the shipper determines a price schedule $\mathbf{p}=\left(p_{1}, p_{2}\right)$. (3) The price schedule $\mathbf{p}$ is announced to overseas customers, according to which the customers make decisions about when to purchase to maximize their utility. (4) Shipments are made based on the volume requested by customers and let $d_{i}(\mathbf{p})$ denote the demand for the product shipped via carrier $i$. The distribution of $\theta$ and the values of $c_{i}$ are common knowledge to the shipper and the carriers. ${ }^{7}$

In sum, we have a two-stage game-theoretical framework. In the first stage, carriers are engaged in a game of simultaneous pricing. Let $r_{-i}$ represent the freight rates charged by the competitor of carrier $i$. For any given $r_{-i}$, carrier $i$ solves

$$
\max _{r_{i}} \Pi_{c i}\left(r_{i} \mid r_{-i}\right)=\left(r_{i}-c_{i}\right) v_{i}(\mathbf{r})
$$

\footnotetext{
${ }^{6}$ The assumption of deterministic transportation times enables us to concentrate on the service differentiation in terms of speeds. In practice, transportation times may be uncertain due to disruptions, and this reliability issue is beyond the scope of this paper but has been studied by Lu et al. (2017).

${ }^{7}$ For example, fuel consumption costs normally account for a major part of the operating cost for carriers (Notteboom and Vernimmen, 2009). Hence, the shipper is able to infer $c_{i}$ from public information such as bunker prices. It is also possible for carriers to estimate the market value of the shipment based on the product. That said, some level of information asymmetry does exist in practice and deserves further research.
} 
where $v_{i}(\mathbf{r})=d_{i}\left(\mathbf{p}^{*}(\mathbf{r})\right)$, representing the shipping volume assigned to carrier $i . \mathbf{p}^{*}(\mathbf{r})$ is the price schedule chosen optimally by the shipper given a set of freight rates $\mathbf{r}$. Let $\mathbf{r}^{N}=\left(r_{1}^{N}, r_{2}^{N}\right)$ be the set of freight rates that constitutes a Nash equilibrium. Then, $\mathbf{r}^{N}$ satisfies

$$
r_{i}^{N}=\arg \max _{r_{i}} \Pi_{c i}\left(r_{i} \mid r_{-i}^{N}\right), \text { for all } i
$$

In the second stage, given a set of freight rates $\mathbf{r}$, the shipper determines the optimal selling price schedule $\mathbf{p}^{*}(\boldsymbol{r})$ to maximize its profit. We define $w_{i}=c_{p}+r_{i}+h t_{i}$ for $i=1,2$, which represents the full variable cost of using carrier $i$, including the production cost, the shipping cost and the inventory holding cost during transportation. Note that $\boldsymbol{w}=\left(w_{1}, w_{2}\right)$ is influenced by the freight rates and is thus endogenously determined by the equilibrium of carrier competition. Given any $\boldsymbol{w}$, the shipper's problem can be written as

$$
\max _{\mathbf{p}} \Pi_{s}(\mathbf{p})=\sum_{i=1}^{2} p_{i} d_{i}(\mathbf{p})-\sum_{i=1}^{2} w_{i} d_{i}(\mathbf{p}),
$$

The demand function $\boldsymbol{d}(\mathbf{p})=\left(d_{1}(\boldsymbol{p}), d_{2}(\boldsymbol{p})\right)$ can be explicitly derived from the customer utility function, which is discussed later.

\section{Results}

\subsection{The Optimal Shipping Strategies}

We analyze the game backward. We start by deriving the demand function $\boldsymbol{d}(\mathbf{p})$ for any given price schedule $\boldsymbol{p}$. Given transportation times $\mathbf{t}$ and price schedule $\mathbf{p}$, customers choose from the two purchasing options characterized by the pairs $\left(q\left(t_{i}\right), p_{i}\right)=\left(a-t_{i}, p_{i}\right)$. Define $t_{3}=a$ and $p_{3}=0$ such that $\left(q\left(t_{3}\right), p_{3}\right)=(0,0)$ represents the no-purchase option. Recall that the gross utility of customers is given by $\theta\left(a-t_{i}\right)$. As a consequence, a type- $\theta$ customer decides when to buy the product by solving the following problem:

$$
\max _{i=1,2,3}\left\{\theta\left(a-t_{i}\right)-p_{i}\right\}
$$

Given any price schedule $p$, there is a pair of cutoff points $\left(\theta_{1}, \theta_{2}\right)$ with $0 \leq \theta_{2} \leq \theta_{1} \leq \bar{\theta}$ such that customers with type $\theta \in\left(\theta_{1}, \bar{\theta}\right]$ choose to purchase the product with quality $a-t_{1}$, those with $\theta \in\left(\theta_{2}, \theta_{1}\right]$ choose the product with quality $a-t_{2}$, and all other customers with $\theta \in\left[0, \theta_{2}\right]$ purchase nothing. Moreover, the cutoffs $\left(\theta_{1}, \theta_{2}\right)$ have a one-to-one mapping with 
the price schedule $\mathbf{p}=\left(p_{1}, p_{2}\right)$ through $\theta_{i}=\frac{p_{i}-p_{i+1}}{t_{i+1}-t_{i}}$ for $i=1,2 .{ }^{8}$ Consequently, the demand functions $d_{i}(\mathbf{p})$ can be expressed as functions of $\Theta: d_{1}(\Theta)=\bar{\theta}-\theta_{1}$ and $d_{2}(\Theta)=\theta_{1}-\theta_{2}$. We can therefore characterize the optimal solution to the shipper's problem (3) with the optimal cutoff vector $\Theta^{*}$ instead of the optimal price schedule $\mathbf{p}^{*}$ with the understanding of $\theta_{i}=\frac{p_{i}-p_{i+1}}{t_{i+1}-t_{i}}$ for all $i$. The following proposition characterizes the shipper's optimal shipping strategy given any fixed full variables costs. For ease of exposition, we use the shorthand notation $\Delta_{t}=t_{2}-t_{1}>0$ and $\gamma=\frac{a-t_{1}}{a-t_{2}}>1$, which are frequently used throughout the paper. The proofs of the main results in this paper are included in the Online Appendix.

Proposition 1. For any given full variable costs $\boldsymbol{w}=\left(w_{1}, w_{2}\right)$, the shipper's optimal cutoffs are given by one of the following cases: (i) if

$$
\begin{aligned}
& w_{1} \leq w_{2}+\bar{\theta} \Delta_{t}, \\
& \text { and } w_{1} \geq \gamma w_{2},
\end{aligned}
$$

then use both carriers and $\theta_{1}^{*}=\frac{1}{2}\left(\frac{w_{1}-w_{2}}{\Delta_{t}}+\bar{\theta}\right)$ and $\theta_{2}^{*}=\frac{1}{2}\left(\frac{w_{2}}{a-t_{2}}+\bar{\theta}\right)$. (ii) if $w_{1}<\gamma w_{2}$ and $w_{1}<\bar{\theta}\left(a-t_{1}\right)$, then use only carrier 1 and $\theta_{1}^{*}=\theta_{2}^{*}=\frac{1}{2}\left(\frac{w_{1}}{a-t_{1}}+\bar{\theta}\right)$; (iii) if $w_{1}>w_{2}+\bar{\theta} \Delta_{t}$ and $w_{2}<\bar{\theta}\left(a-t_{2}\right)$, then use only carrier 2 and $\theta_{1}^{*}=\bar{\theta}$ and $\theta_{2}^{*}=\frac{1}{2}\left(\frac{w_{2}}{a-t_{2}}+\bar{\theta}\right)$; (iv) otherwise (i.e., when $w_{i} \geq \bar{\theta}\left(a-t_{i}\right)$ for all $\left.i=1,2\right)$, ship nothing and $\theta_{1}^{*}=\theta_{2}^{*}=\bar{\theta}$;

Cases (i)-(iii) characterize the conditions under which the shipper should use both carriers 1 and $2\left(\bar{\theta}>\theta_{1}^{*}>\theta_{2}^{*}\right)$, only carrier $1\left(\bar{\theta}>\theta_{1}^{*}=\theta_{2}^{*}\right)$ and only carrier $2\left(\bar{\theta}=\theta_{1}^{*}>\theta_{2}^{*}\right)$, respectively. In case (iv), both variable costs are too high and neither carrier should be used. In particular, inequalities (4) and (5) characterize the conditions under which dual-mode shipping, i.e., using both carriers, is optimal.

Graphically, Figure 1 depicts the optimal shipping volumes $\left(v_{1}(\mathbf{w}), v_{2}(\mathbf{w})\right)$ for any given full variable costs $\mathbf{w}$. When the full variable cost of carrier $i$ is much more attractive than that of the other carrier, the shipper would use exclusively carrier $i$ and deliver a volume of $\frac{1}{2}\left(\bar{\theta}-\frac{w_{i}}{a-t_{i}}\right)$ with quality $a-t_{i}$. When neither of the full variable costs is substantially more attractive than the other, i.e., inequalities (4) and (5) are satisfied, the shipper would deliver a volume of $\frac{1}{2}\left(\bar{\theta}-\frac{w_{1}-w_{2}}{\Delta_{t}}\right)$ with quality $a-t_{1}$ and another volume of $\frac{1}{2}\left(\frac{w_{1}-w_{2}}{\Delta_{t}}-\frac{w_{2}}{a-t_{2}}\right)$ with quality $a-t_{2}$. The product in this case will be delivered with different qualities, essentially serving as a product differentiation strategy.

By the relation $\theta_{i}=\frac{p_{i}-p_{i+1}}{t_{i+1}-t_{i}}$, one can translate $\Theta^{*}$ to the optimal price schedule $\left(p_{1}^{*}, p_{2}^{*}\right)$ that the shipper should charge at two time points. When the dual-mode is optimal, the optimal prices

\footnotetext{
${ }^{8}$ This result has been shown and used in the vertical quality differentiation literature (e.g., Pan and Honhon, 2012; Chen et al., 2013).
} 


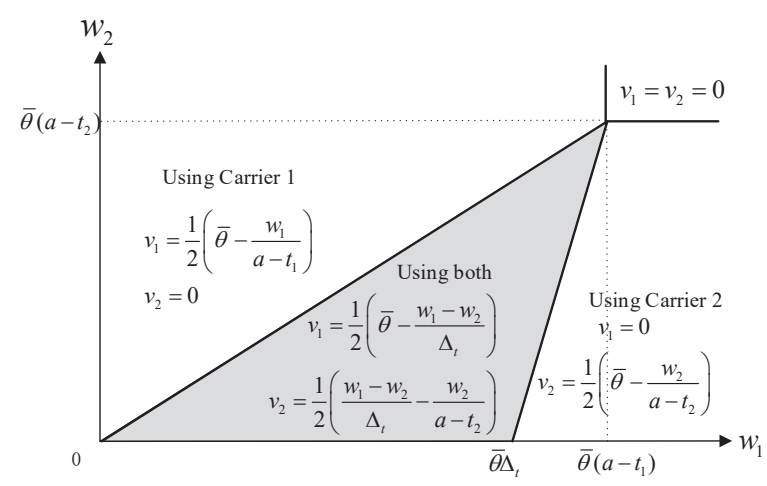

Figure 1: The optimal shipping volumes for any given full variable costs $\boldsymbol{w}=\left(w_{1}, w_{2}\right)$

are given by $p_{i}^{*}=\frac{1}{2}\left[w_{i}+\bar{\theta}\left(a-t_{i}\right)\right]$ for both $i$. This may be viewed as a markup pricing policy. The selling price of the shipment via carrier $i$ is calculated based only on variable cost $w_{i}$ and transportation time $t_{i}$. Moreover, the markup term $\bar{\theta}\left(a-t_{i}\right)$ is higher for the shipment supplied via carrier 1, which can be interpreted as a price "premium" for the high-quality product. Under dual-mode shipping, the first shipment via carrier 1 is delivered faster and sells at a higher price, whereas the second shipment via carrier 2 reaches the market more slowly and has a lower selling price; but the slow shipment allows the shipper to capture market segments in which customers are not particularly sensitive to delivery time. This result appears consistent with the earlier quoted anecdotal evidence: When mangoes are shipped from Mali via sea freight instead of only air freight, Malians were able to export in higher volumes and reach broader markets instead of only the current niche market, as sea-freighted mangoes are more cost competitive (Sangho et al., 2011, p. 18).

\subsection{Characterization of the Nash Equilibrium}

Having analyzed the shipper's optimal decision, we proceed to analyze price competition between carriers. To begin, we define $w_{i}^{o}=c_{i}+h t_{i}+c_{p}$ which represents the minimum full variable cost of using carrier $i$, as it equals the full variable cost for the shipper when carrier $i$ charges its marginal cost. In some sense, the lower $w_{i}^{o}$ is, the higher carrier $i$ 's cost efficiency. We assume $w_{i}^{o} \in\left[0, \bar{\theta}\left(a-t_{i}\right)\right]$ for all $i$ without loss of generality, because by Proposition 4 , if $w_{i}^{o} \geq \bar{\theta}\left(a-t_{i}\right)$ for some $i$, then regardless of the competitor's quote, carrier $i$ cannot obtain any business even when its freight rate $r_{i}$ is equal to the marginal operating $\operatorname{cost} c_{i}$. Recall that carriers simultaneously determine their freight rates while anticipating the shipper's optimal responses, as characterized in Section 4.1. Because $c_{p}, h$ and $t_{i}$ are given parameters, optimizing over $r_{i} \geq c_{i}$ is equivalent to optimizing over the full variable cost $w_{i}=r_{i}+h t_{i}+c_{p} \geq w_{i}^{o}$ for carrier $i$. We can thus rewrite 
carrier $i$ 's problem (1) as the following.

$$
\max _{w_{i} \geq w_{i}^{o}} \Pi_{c i}\left(w_{i} \mid w_{-i}\right)=\left(w_{i}-w_{i}^{o}\right) v_{i}(\mathbf{w}),
$$

By solving Problem (6), we can characterize each carrier's best response function in closed form, which is detailed in Proposition B.1 (see Appendix B).

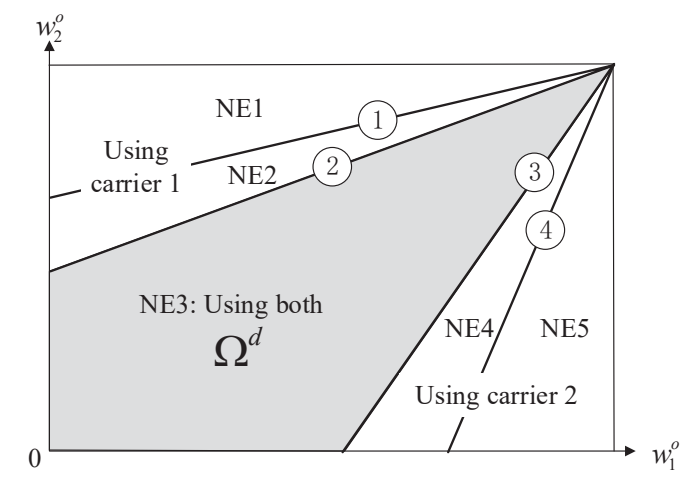

$$
\begin{aligned}
& \text { Line (1) } w_{2}^{o}=\frac{1}{2 \gamma}\left[w_{1}^{o}+\bar{\theta}\left(a-t_{1}\right)\right] \text { (3) } w_{2}^{o}=\frac{2 \gamma-1}{\gamma} w_{1}^{o}-2 \bar{\theta} \Delta_{t} \\
& \text { segments: (2) } w_{2}^{o}=\frac{w_{1}^{o}+\bar{\theta} \Delta_{t}}{2 \gamma-1} \quad \text { (4) } w_{2}^{o}=2 w_{1}^{o}-(2 \gamma-1) \bar{\theta}\left(a-t_{2}\right)
\end{aligned}
$$

Figure 2: Illustration of possible Nash equilibria

In Theorem 1, we show that there is a unique Nash equilibrium in the carrier competition, and the equilibrium freight rates (expressed with $\boldsymbol{w}$ ) are derived in closed form.

Theorem 1. In price competition between carriers, there is a unique Nash equilibrium $\left(w_{1}^{N}, w_{2}^{N}\right)$ given by one of the following five cases:

(i) If $w_{1}^{o} \leq 2 \gamma w_{2}^{o}-\bar{\theta}\left(a-t_{1}\right)$, then

$$
(N E 1) \quad w_{1}^{N}=\frac{w_{1}^{o}+\bar{\theta}\left(a-t_{1}\right)}{2}, \quad w_{2}^{N}=w_{2}^{o}
$$

(ii) If $2 \gamma w_{2}^{o}-\bar{\theta}\left(a-t_{1}\right)<w_{1}^{o} \leq(2 \gamma-1) w_{2}^{o}-\bar{\theta} \Delta_{t}$, then

$$
\text { (NE2) } w_{1}^{N}=\gamma w_{2}^{o}, \quad w_{2}^{N}=w_{2}^{o}
$$

(iii) If $(2 \gamma-1) w_{2}^{o}-\bar{\theta} \Delta_{t}<w_{1}^{o} \leq \frac{\gamma w_{2}^{o}+2 \gamma \bar{\theta} \Delta_{t}}{2 \gamma-1}$, then

$$
\text { (NE3) } w_{1}^{N}=\frac{2 \gamma w_{1}^{o}+\gamma w_{2}^{o}+2 \gamma \bar{\theta} \Delta_{t}}{4 \gamma-1}, \quad w_{2}^{N}=\frac{w_{1}^{o}+2 \gamma w_{2}^{o}+\bar{\theta} \Delta_{t}}{4 \gamma-1} .
$$


(iv) If $\frac{\gamma w_{2}^{o}+2 \gamma \bar{\theta} \Delta_{t}}{2 \gamma-1}<w_{1}^{o} \leq \frac{w_{2}^{o}+(2 \gamma-1) \bar{\theta}\left(a-t_{2}\right)}{2}$, then

$$
\left(N E_{4}\right) \quad w_{1}^{N}=w_{1}^{o}, \quad w_{2}^{N}=w_{1}^{o}-\bar{\theta} \Delta_{t}
$$

(v) If $w_{1}^{o}>\frac{w_{2}^{o}+(2 \gamma-1) \bar{\theta}\left(a-t_{2}\right)}{2}$, then

$$
\text { (NE5) } w_{1}^{N}=w_{1}^{o}, \quad w_{2}^{N}=\frac{w_{2}^{o}+\bar{\theta}\left(a-t_{2}\right)}{2} .
$$

"NE" in the theorem is short for the Nash equilibrium. The shipper only uses carrier 1 in NE1 and NE2. The difference between NE1 and NE2 is that in NE1, carrier 1 can charge a monopolistic price as if its competitor were not present, whereas in NE2 carrier 1 retains all of the business but competition from carrier 2 brings its freight rate down from monopoly. Likewise, the shipper exclusively uses carrier 2 in NE4 and NE5, and carrier 2 charges a monopolistic price in NE5 but is unable to do so in NE4. In NE3, neither carrier can win the entire business and the shipper adopts a dual-mode shipping strategy that leads to product differentiation in the destination market. ${ }^{9}$

To take a first glimpse of the implications of carrier competition, let us imagine a setting where the three parties (the shipper and two carriers) are governed by a central planner. In such a scenario, one can regard the operating $\operatorname{costs} c_{1}$ and $c_{2}$ as the freight rates quoted by carriers 1 and 2. From Proposition 1, it can be seen that in this centralized setting, dual-mode shipping is never optimal if the faster carrier operates at a lower cost, i.e., $c_{1}<c_{2}$. However, this is not true when carriers compete and strategically decide on the freight rates.

Proposition 2. The shipper may use both carriers in the Nash equilibrium even when $c_{1}<c_{2}$.

As shown in Proposition 2, even when the slower carrier operates at a higher cost, it may still receive some business in equilibrium. In other words, the carrier competition makes the shipper more likely to use dual-mode shipping. From the customers' perspective, this suggests that carrier competition may increase the variety of products supplied in the end market.

\subsection{The Effect of Transportation Times}

As established in Proposition B.5 of Appendix B, if freight rates are given, then the shipper's profit always decreases as either carrier slows down. Nevertheless, in this subsection, we show that the shipper's profit may not be monotonic in the fast carrier's speed when freight rates

\footnotetext{
${ }^{9}$ To implement the threatening strategies in NE2 and NE4 in reality, the shipper may invite both carriers to bid.
} 
are an equilibrium outcome of the carrier competition. In what follows, we focus on the dualmode shipping equilibrium, i.e., NE3 as stated in Theorem 1. Proposition 3 presents a set of comparative static results on the shipper's variable costs $w_{i}^{N}$ 's and profit $\Pi_{s}^{N}=\Pi_{s}\left(\mathbf{w}^{N}\right)$. The terms increasing and decreasing are used in the weak sense throughout the paper.

Proposition 3. If dual-mode shipping is adopted in equilibrium, then the following statements hold true: (i) If $\frac{2 w_{1}^{o}+w_{2}^{o}}{a-t_{2}} \leq \min \left\{\frac{3 \bar{\theta}-(4 \gamma-1) h}{2}, 2 \bar{\theta}\left(4 \gamma^{2}-2 \gamma+1\right)-\left(8 \gamma^{2}-2 \gamma\right) h\right\}$, both $w_{1}^{N}$ and $w_{2}^{N}$ are decreasing in $t_{1}$; if $h \leq \bar{\theta} / 2, w_{1}^{N}$ is always decreasing in $t_{1}$; if $h=0$ and $c_{1} \neq c_{2}$, there exists $a \hat{\gamma}>1$ such that $\Pi_{s}^{N}$ is increasing in $t_{1}$ for all $1<\gamma \leq \hat{\gamma}$; (ii) $w_{1}^{N}$ is always increasing in $t_{2}$; if $\frac{4 w_{1}^{o}+2 w_{2}^{o}}{a-t_{2}} \leq(8 \gamma-2) h+\bar{\theta}\left(8-\frac{1}{\gamma}-4 \gamma\right), w_{2}^{N}$ is also increasing in $t_{2}$, and so $\Pi_{s}^{N}$ is decreasing in $t_{2}$.

Part (i) of Proposition 3 shows that as $t_{1}$ increases, both variable costs for the shipper can be lower in equilibrium, given that inventory holding cost $h$ is small or the highest market valuation $\bar{\theta}$ is large. The key driver for these results is that a smaller gap between $t_{1}$ and $t_{2}$ makes carrier competition more intense and thus reduces the freight rates in equilibrium. As long as $h \leq \frac{\bar{\theta}}{2} 10$, a greater $t_{1}$ always lowers $w_{1}^{N}$. It can be shown that the shipper's profit function $\Pi_{s}(\boldsymbol{w})$ for any fixed $w_{i}$ 's is decreasing in all $t_{i}$ 's and $w_{i}$ 's (see Proposition B.5). Hence, there are two countervailing forces that determine the aggregate effect of $t_{1}$ on the shipper's profit: An increase in $t_{1}$ always results in operational inefficiency, but it can also create a cost advantage due to lower freight rates in equilibrium. While it is intractable to fully characterize this aggregate effect, part (i) of Proposition 3 establishes that in the special case in which the inventory holding cost is zero and carriers' operating costs are not equal, the shipper's profit $\Pi_{s}^{N}$ is increasing in $t_{1}$ when $t_{1}$ and $t_{2}$ are sufficiently close. This demonstrates that the cost advantage due to carrier competition may outweigh operational efficiency.

However, an increase in $t_{2}$ reduces operational efficiency. It also enlarges the gap between $t_{1}$ and $t_{2}$, thus weakening the intensity of competition and reducing the shipper's cost advantage. As indicated by part (ii) of Proposition 3, carrier 1 always raises its freight rate as $t_{2}$ increases. We also provide the condition ${ }^{11}$ under which an increase in $t_{2}$ also makes $w_{2}^{N}$ higher and consequently lowers the shipper's profit. If this condition does not hold, while $w_{2}^{N}$ can be decreasing in $t_{2}$, all of our numerical experiments suggest that an increase in $t_{2}$ still lowers the shipper's profit as an aggregate effect.

Next, we report a numerical study to investigate the aggregate effect of transportation times

\footnotetext{
${ }^{10}$ This is a very mild condition, implying that for one unit reduction of transportation time, the average increase in customers' utility is greater than the inventory holding cost.

${ }^{11}$ To interpret the condition, assuming $h=0$, one can show that the right-hand side of the inequality is decreasing in $\gamma$. This implies that for a relatively high $\bar{\theta}$, the inequality holds if and only if $\gamma$ is smaller than a threshold. In other words, carrier 2 can possibly raise its freight rate as it becomes slower when $t_{1}$ and $t_{2}$ are close enough and the maximum market valuation is relatively high.
} 

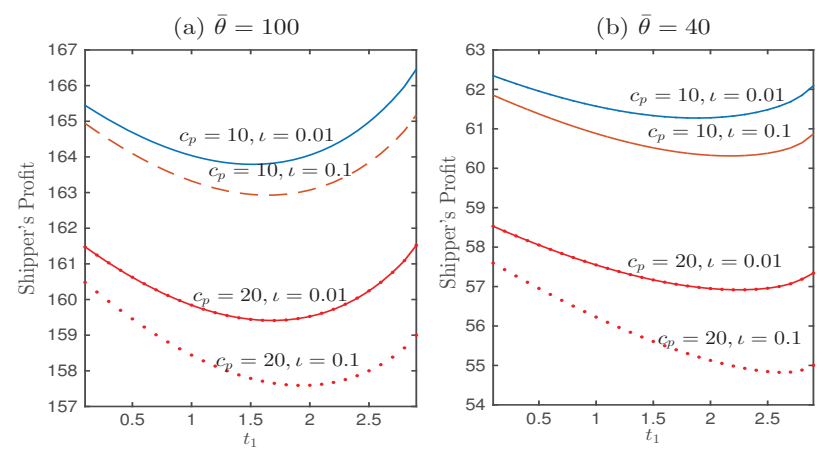

Figure 3: Impact of $t_{1}$ on the shipper's profit (with $t_{2}=3$ )

on the shipper's profit in more general cases. As mentioned earlier, we observed in all of our numerical instances that the shipper is worse off as $t_{2}$ increases. We therefore focus on the effect of $t_{1}$ in what follows. In the numerical study, we assume the inventory holding cost $h=\iota c_{p}$ where $\iota$ represents the interest rate used in the calculation of $h$. Having proved that the shipper's profit may increase with $t_{1}$ as the cost advantage due to competition dominates operational efficiency when $t_{1}$ is close to $t_{2}$, we can further infer that the effect of $t_{1}$ should be reversed when $t_{1}$ is much smaller than $t_{2}$; in such cases, carrier competition is reduced and the operational efficiency becomes dominant. This reasoning is verified in Figure 3 which shows that the shipper's profit is $\mathrm{U}$-shaped with respect to $t_{1}$. In Figure $3, t_{1}$ varies from 0.1 to 2.9 with $t_{2}$ being fixed at $3 .{ }^{12}$ With different values of $\bar{\theta}, c_{p}$ and $\iota$ as indicated, we find that the shipper's U-shaped profit becomes more downward sloping when $\bar{\theta}$ is lower or $\iota$ are higher, indicating that sourcing from similar services (in terms of speed) brings more benefit in a market with higher valuation and heterogeneity, or when the product is procured and held as inventory at a lower cost. Intuitively, a higher inventory holding cost makes the two carriers more distinct from each other because of the pipeline inventory, thus weakening the competition effect in some sense.

As for the influence of transportation times on each carrier's profit, one might anticipate that an individual carrier is worse off having a faster competitor. However, this is not necessarily true. In Figure 4, we plot freight rates $r_{i}^{N}$, shipping volumes $v_{i}^{N}$ and carriers' profits $\Pi_{c i}^{N}$ in equilibrium as either $t_{1}$ or $t_{2}$ varies. ${ }^{13}$ As shown in Figure $4(\mathrm{a})$, when carrier 1 speeds up, i.e., $t_{1}$ becomes smaller, carrier 2 may raise its freight rate, which echoes our analytical finding in part (i) of Proposition 3 and improves its profit. In other words, the slow carrier may be a free rider as its competitor speeds up further, as more distinct transportation times reduce competition. In contrast, we also observed that carrier 1 is always worse off slowing down its service. Figure 4(b) shows that as $t_{2}$ increases, both carriers may increase freight rates, as indicated by part

\footnotetext{
${ }^{12}$ The other parameters are set as $a=10, c_{1}=10$ and $c_{2}=2$.

${ }^{13}$ In the numerical examples in Figure $4, \bar{\theta}=40, c_{p}=20, \iota=0.01, a=10, c_{1}=10$ and $c_{2}=2$.
} 

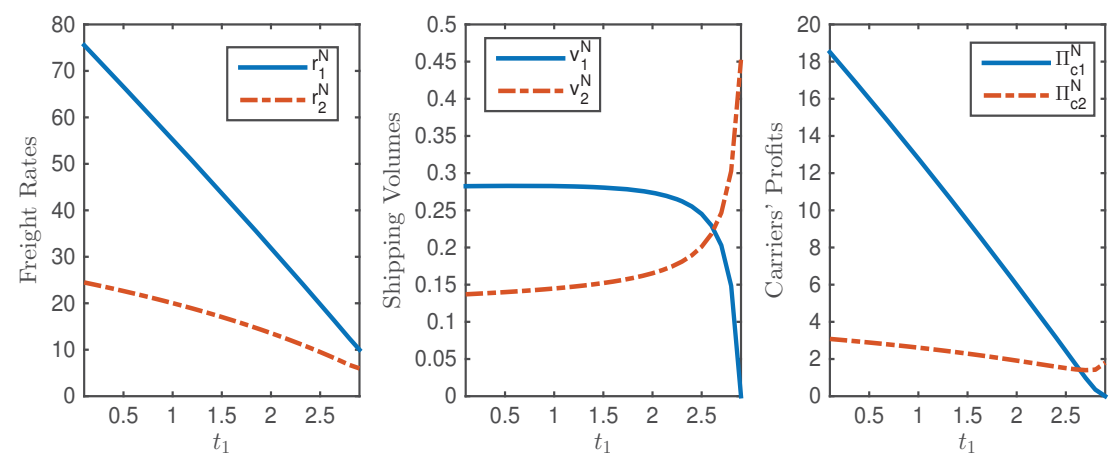

(a) Varying $t_{1}$ from 0.1 to 2.9 with $t_{2}=3$
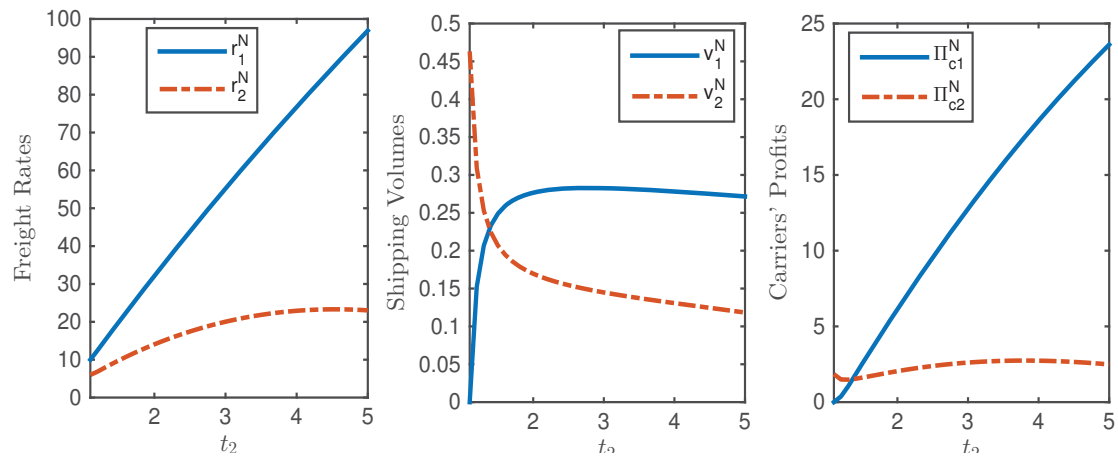

(b) Varying $t_{2}$ from 1.1 to 5 with $t_{1}=1$

Figure 4: Impact of the transportation times on freight rates, shipping volumes and carriers' profits

(ii) of Proposition 3. Moreover, carrier 2 may improve its profit by reducing its speed and distinguishing itself from the competitor, but the benefit of slowing down can be dominated by the operational inefficiency when $t_{2}$ drops too much. Another interesting observation is that while carrier 1 is always better off as $t_{2}$ increases, it may receive a smaller volume $v_{1}^{N}$ as its competitor becomes slower.

To recap our main findings, the shipper's profit is U-shaped in the difference between the speeds of two carriers due to a tension between operational efficiency and cost advantage. The U-shaped profit curve suggests that under dual-mode shipping, the shipper should use two carriers with either substantially distinct or very similar speeds to leverage either the operational advantage or the cost advantage. Using two moderately different services may be harmful. From the slow carrier's perspective, it is sometimes beneficial to have a faster competitor or to further slow itself down. This finding has implications on the recent practice of slow steaming in ocean transport (e.g., Lee et al., 2015a). In addition to cost reduction, ocean liners can potentially benefit from slow steaming to differentiate themselves from faster competitors (e.g., airline or rail). 


\subsection{Single Sourcing vs. Dual Sourcing}

In the base model, we presumed a procurement strategy whereby the shipper allows the possibility of dual-mode shipping and both carriers are informed of this possibility at the beginning of the game. We will refer to this strategy, i.e., the game setup that we have analyzed so far, as the dual-sourcing strategy. Note that we make a distinction between the two terms, dual-mode shipping and dual sourcing. Under a dual sourcing strategy, the shipper may end up using either one or two carriers, depending on which of the Nash equilibria characterized in Theorem 1 is reached.

In this subsection, we consider an alternative procurement strategy, the single-sourcing strategy, defined as follows. The shipper restricts itself to a single shipping service, and carriers are aware that they will be selected in a winner-take-all fashion. Under this single-sourcing strategy, the carrier that is not chosen will lose out on the entire business; as such, carriers will be engaged in a Bertrand-type competition and the winner will set its price such that the competitor finds it unprofitable to compete for the business. Proposition B.2 in Appendix B details the characterization of the Nash equilibrium, denoted by $\left(w_{1}^{S}, w_{2}^{S}\right)$, under the single-sourcing strategy. In the following discussion, we denote by $\Pi_{s}^{S}$ the shipper's profit in the single-sourcing equilibrium and it can be shown that $\Pi_{s}^{S}=\max _{i} \frac{\left[\bar{\theta}\left(a-t_{i}\right)-w_{i}^{S}\right]^{2}}{4 \bar{\theta}\left(a-t_{i}\right)}$. Note that if freight rates are exogenously given, then single sourcing can never perform better than dual sourcing, as it restricts the feasible region of the shipper's problem. Nevertheless, as will be shown below, single sourcing may outperform dual sourcing when carriers competitively determine their freight rates.

We are particularly interested in the question of whether the shipper is better off with single sourcing when dual-mode shipping is indeed an equilibrium in our base model. We define a set $\Omega^{d}=\left\{\left(w_{1}^{o}, w_{2}^{o}\right) \in \mathbb{R}_{+}^{2}: w_{1}^{L}\left(w_{2}^{o}\right) \leq w_{1}^{o} \leq w_{1}^{U}\left(w_{2}^{o}\right)\right\}$ where $w_{1}^{L}\left(w_{2}^{o}\right)=\max \left\{(2 \gamma-1) w_{2}^{o}-\bar{\theta} \Delta_{t}, 0\right\}$ and $w_{1}^{U}\left(w_{2}^{o}\right)=\frac{\gamma w_{2}^{o}+2 \gamma \bar{\theta} \Delta_{t}}{2 \gamma-1}$. By Theorem 1, the set $\Omega^{d}$ consists of all possible $\left(w_{1}^{o}, w_{2}^{o}\right)$ that lead to NE3, i.e., dual-mode shipping, in Theorem 1. The following theorem proves that single sourcing outperforms dual sourcing if and only if $\left(w_{1}^{o}, w_{2}^{o}\right)$ falls in a middle region of $\Omega^{d}$.

Theorem 2. For any $\left(w_{1}^{o}, w_{2}^{o}\right) \in \Omega^{d}$ with $w_{2}^{o}$ being fixed, there exist two thresholds $\underline{\phi}\left(w_{2}^{o}\right) \leq \bar{\phi}\left(w_{2}^{o}\right)$ within $\left[w_{1}^{L}\left(w_{2}^{o}\right), w_{1}^{U}\left(w_{2}^{o}\right)\right]$ such that (i) $\Pi_{s}^{S} \geq \Pi_{s}^{N}$ if $w_{1}^{o} \in\left[\underline{\phi}\left(w_{2}^{o}\right), \bar{\phi}\left(w_{2}^{o}\right)\right]$ and (ii) $\Pi_{s}^{S} \leq \Pi_{s}^{N}$ if $w_{1}^{o} \in\left[w_{1}^{L}\left(w_{2}^{o}\right), \underline{\phi}\left(w_{2}^{o}\right)\right) \cup\left(\bar{\phi}\left(w_{2}^{o}\right), w_{1}^{U}\left(w_{2}^{o}\right)\right]$.

Figure 5(a) visualizes Theorem 2 with a specific example ${ }^{14}$ in which the thresholds' dependence on $w_{2}^{o}$ is omitted for brevity. In particular, the kink point of $\Pi_{s}^{S}$ in the middle, which occurs at $w_{1}^{o}=w_{1}^{P}$, is attained when single sourcing gives rise to a "perfect" or, in other words,

\footnotetext{
${ }^{14}$ In the example of Figures $5(\mathrm{a})$ and $5(\mathrm{~b}), \bar{\theta}=50, t_{1}=3, t_{2}=6, a=10$. In particular, $w_{2}^{o}$ is fixed at 100 in Figure 5(a).
} 


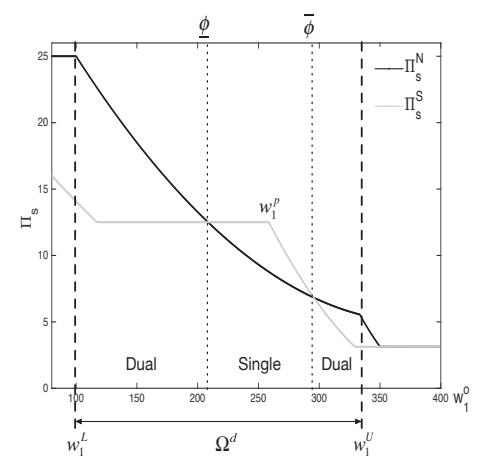

(a) $\Pi_{s}^{S}$ vs. $\Pi_{s}^{N}$ for a fixed $w_{2}^{o}$

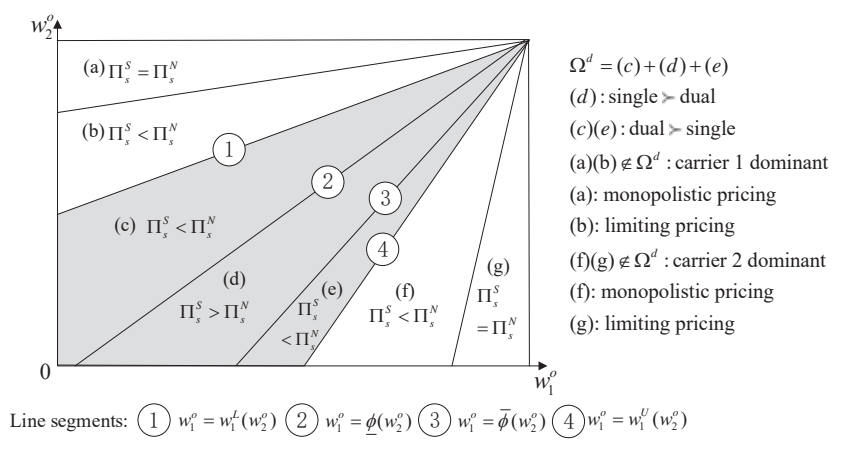

(b) $\Pi_{s}^{S}$ vs. $\Pi_{s}^{N}$ for all $\left(w_{1}^{o}, w_{2}^{o}\right)$

Figure 5: Comparison between the profits under single sourcing and dual sourcing

the most intense competition in the sense that both carriers price at their marginal costs (see Proposition B.3 in Appendix B for a closed-form expression of $\left.w_{1}^{P}\right)$. Single sourcing may therefore trigger more intense competition as compared to dual sourcing, which enables the shipper to better leverage the cost advantage from carrier competition especially when $w_{1}^{o}$ is in the vicinity of $w_{1}^{P}$. However, being restricted to a single carrier, the shipper has to sacrifice the value of product differentiation. Our analysis shows that the shipper may be better off forgoing product differentiation and instead taking full advantage of carrier competition via single sourcing. Theorem 2 uncovers this underlying trade-off between product differentiation and carrier competition exploitation. Figure $5(\mathrm{~b})^{15}$ presents a full picture of the comparison between the two sourcing strategies for all pairs of $\left(w_{1}^{o}, w_{2}^{o}\right)$, including those not in $\Omega^{d}$. In Appendix B, Proposition B.4 establishes that for $\left(w_{1}^{o}, w_{2}^{o}\right) \notin \Omega^{d}$, single sourcing is weakly dominated by dual sourcing. ${ }^{16}$

From Theorem 2, we can readily conclude a similar result in terms of carriers' operating $\operatorname{costs} c_{i}$ 's: For any fixed $c_{2}$, there exist two thresholds $c_{1}^{L}$ and $c_{1}^{U}$ such that single sourcing is preferred if and only if $c_{1}$ lies in the interval $\left[c_{1}^{L}, c_{1}^{U}\right]$. To investigate how other parameters shape the boundary conditions between the two sourcing strategies, we conduct a numerical study as shown in Figure 6. In Figures 6(a) and 6(c), we consider a case in which two carriers have identical operating costs $\left(\Delta_{c}=c_{1}-c_{2}=0\right)$. Single sourcing tends to be preferable when $\Delta_{t}=t_{2}-t_{1}$ is smaller such that the competition induced by winner-take-all is closer to perfect (given equal operating costs). A smaller production cost $c_{p}$ makes single sourcing more likely to be favored (Figure 6(a)), because, intuitively, when $c_{p}$ becomes larger, the transportation cost

\footnotetext{
${ }^{15}$ In the examples given in Figure 6, $c_{2}=2, c_{1}=c_{2}+\Delta_{c}, t_{1}=1, t_{2}=t_{1}+\Delta_{t}, h=0.01 c_{p}$.

${ }^{16}$ When one dominant carrier can attract all of the shipments even under the dual sourcing strategy, single sourcing does not intensify the competition but instead endows the dominant carrier with greater pricing power (regions (b) and (f) in Figure 5(b)). Moreover, if the difference between $w_{i}^{o}$ 's is extreme, then the dominant carrier can price as a monopoly such that the shipper is indifferent between single sourcing and dual sourcing (regions (a) and (g) in Figure 5(b)).
} 


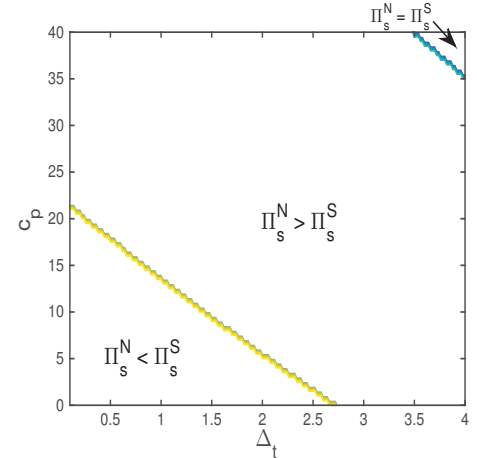

(a) $\Delta_{c}=0$

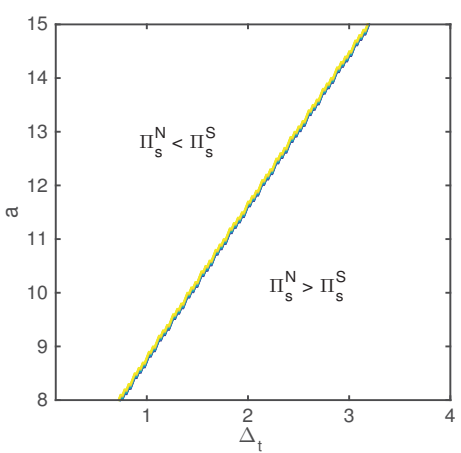

(c) $\Delta_{c}=0$

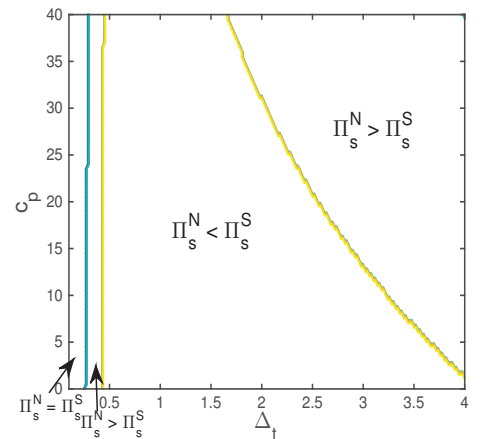

(b) $\Delta_{c}=10$

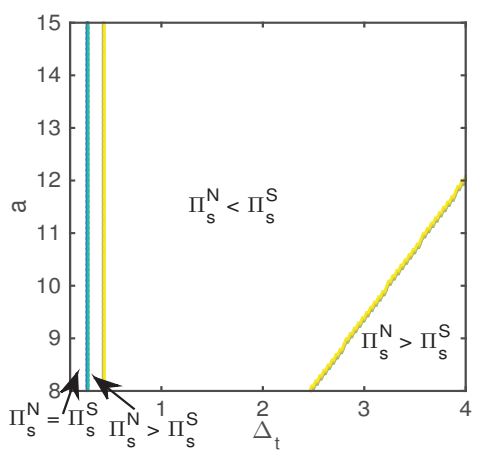

(d) $\Delta_{c}=10$

Figure 6: Impacts of $\Delta_{t}, \Delta_{c}, c_{p}, a$ on the procurement strategies

will account for a smaller portion in the full variable cost $w_{i}=r_{i}+h t_{i}+c_{p}$ (where $h=0.01 c_{p}$ in the numerical example); consequently, this will lessen the additional cost advantage derived from single sourcing. As the potential quality level $a$ increases, the transportation-induced quality differentiation becomes less salient, thus lowering the value of dual sourcing. Hence, single sourcing becomes more favorable when the product has a higher potential quality a (Figure 6(c)). When $c_{1}$ and $c_{2}$ different, as shown in Figures 6(b) and 6(d), an increase in $\Delta_{t}$ may either strengthen or weaken the value of single sourcing, depending on the extent to which $\Delta_{t}$ is aligned with $\Delta_{c}$.

\section{Extensions}

\subsection{Non-uniform Customer Type Distribution}

Our base model assumed that customer type $\theta$ is uniformly distributed. This implies that customers in the market demand similar volumes. In practice, a fruit exporter may sell to big supermarket chains whose purchasing quantities are often larger than other channels such as gourmet stores and neighborhood groceries. To incorporate this more realistic situation in 
which customers of different types may demand distinct volumes, we now relax the assumption that customer type $\theta$ is uniformly distributed. We assume that $\theta$ is distributed according to a cumulative distribution function $(\operatorname{cdf}) F(\theta)$ on a support of $[\underline{\theta}, \bar{\theta}]$. Let $f(\theta)$ be the probability density function and $\bar{F}(\theta)=1-F(\theta)$. The density $f(\theta)$ can be interpreted as the demand volume of a customer with type $\theta$; customers vary in demand volume if distribution $F(\theta)$ is not uniform. Throughout this subsection, we assume $F(\theta)$ has an increasing failure rate (IFR), which is satisfied by many common probability distributions (Bagnoli and Bergstrom, 2005). Let $G(\theta)=\theta-\frac{\bar{F}(\theta)}{f(\theta)}$ and $\hat{G}^{-1}(x)=G^{-1}(\max \{x, G(\underline{\theta})\}) .{ }^{17}$ We first show that for given freight rates, the shipper's optimal shipping strategy has the same structure as characterized in Proposition 1.

Proposition 4. Given any $\left(w_{1}, w_{2}\right)$, the optimal shipping strategy and cutoffs $\Theta^{*}=\left(\theta_{1}^{*}, \theta_{2}^{*}\right)$ are given by one of the following cases: (i) if $w_{1} \leq w_{2}+\bar{\theta} \Delta_{t}$ and $w_{1} \geq \gamma w_{2}$, then use both carriers and $\theta_{1}^{*}=\hat{G}^{-1}\left(\frac{w_{1}-w_{2}}{\Delta_{t}}\right)$ and $\theta_{2}^{*}=\hat{G}^{-1}\left(\frac{w_{2}}{a-t_{2}}\right)$. (ii) if $w_{1}<\gamma w_{2}$ and $w_{1}<\bar{\theta}\left(a-t_{1}\right)$, then exclusively use carrier 1 and $\theta_{1}^{*}=\theta_{2}^{*}=\hat{G}^{-1}\left(\frac{w_{1}}{a-t_{1}}\right)$; (iii) if $w_{1}>w_{2}+\bar{\theta} \Delta_{t}$ and $w_{2}<\bar{\theta}\left(a-t_{2}\right)$, then exclusively use carrier 2 and $\theta_{1}^{*}=\bar{\theta}$ and $\theta_{2}^{*}=\hat{G}^{-1}\left(\frac{w_{2}}{a-t_{2}}\right)$; (iv) otherwise (i.e., when $w_{i} \geq \bar{\theta}\left(a-t_{i}\right)$ for all $i=1,2)$, then ship nothing and $\theta_{1}^{*}=\theta_{2}^{*}=\bar{\theta}$.

Next, we establish the log-supermodularity of the generalized carrier competition under the following regularity condition on distribution $F$ :

$$
(\mathrm{R}): f(\theta) \text { is (weakly) decreasing, and } \frac{f^{\prime}(\theta) \bar{F}(\theta)}{(f(\theta))^{2}} \text { is (weakly) increasing. }
$$

Condition $(\mathrm{R})$ requires a decreasing density function. In other words, demand in lower-end segments is larger, which is consistent with anecdotal evidence that the largest segments are comprised of buyers with average purchasing power, e.g., buying sea-freighted mangoes in the EU market (Araújo and Garcia, 2016). In the Supplementary Material for the paper, we have verified that condition $(\mathrm{R})$ is satisfied by the uniform distribution, (truncated) exponential distribution, triangular distribution with decreasing density, power distribution $F(\theta)=1-(1-\theta)^{b}$ with $b \geq 1$, and (truncated) Weibull distribution $F(\theta)=1-e^{-\left(\frac{x}{\lambda}\right)^{k}}$ with $k \leq 1$.

Theorem 3. Under condition $(R)$, carrier $i$ 's profit function $\Pi_{c i}\left(w_{1}, w_{2}\right)$ is log-supermodular in $\left(w_{1}, w_{2}\right)$ for all $i$. The carrier competition has a Nash equilibrium and the set of Nash equilibria is a lattice containing a pair of lowest quotations $\left(\underline{w}_{1}^{N}, \underline{w}_{2}^{N}\right)$ and a pair of highest ones $\left(\bar{w}_{1}^{N}, \bar{w}_{2}^{N}\right)$.

Theorem 3 proves the existence of a Nash equilibrium under condition (R). Furthermore, it implies that the component-wise smallest and largest equilibria, $\left(\underline{w}_{1}^{N}, \underline{w}_{2}^{N}\right)$ and $\left(\bar{w}_{1}^{N}, \bar{w}_{2}^{N}\right)$, can

\footnotetext{
${ }^{17}$ By the IFR of $F, G(\theta)$ is strictly increasing in $\theta$ and its inverse function $G^{-1}$ is thus well defined.
} 
be efficiently computed with a round-robin scheme (see Section 4.3 in Topkis, 1998, for details). If $\left(\underline{w}_{1}^{N}, \underline{w}_{2}^{N}\right)$ and $\left(\bar{w}_{1}^{N}, \bar{w}_{2}^{N}\right)$ are identical, then the game has a unique equilibrium. This enables us to conduct an extensive numerical study with more general customer type distributions.
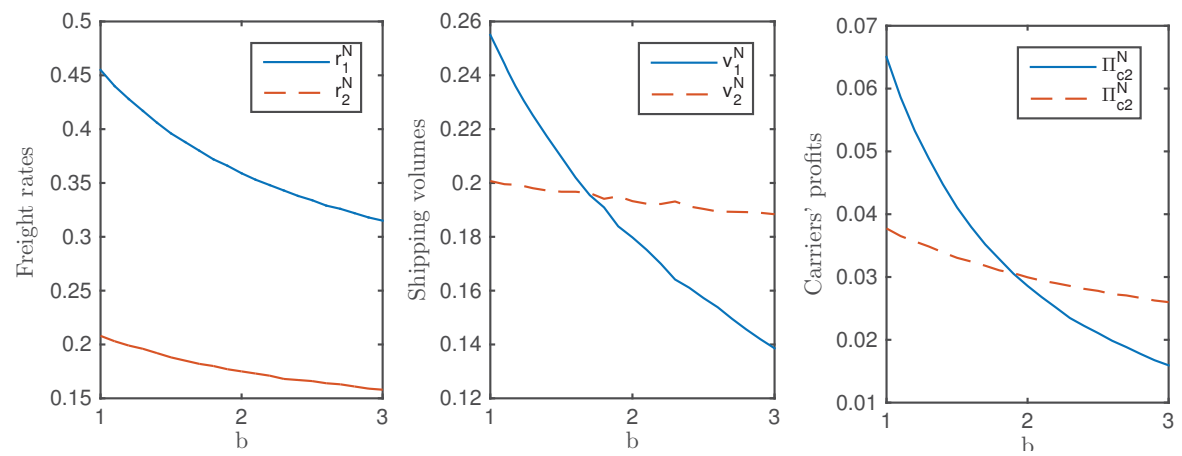

(a) Effect of $b$ on the equilibrium freight rates, shipping volumes, and carriers' profits $\left(t_{1}=2.5, t_{2}=3\right)$

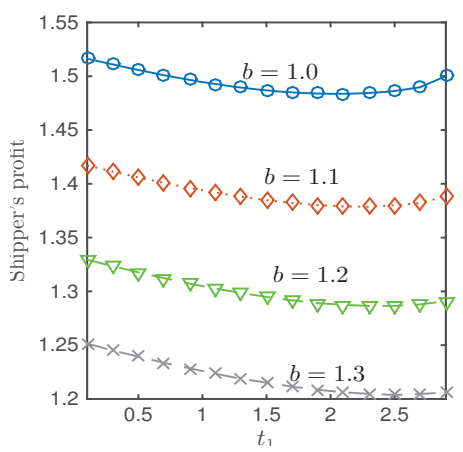

(b) Effect of $b$ on the shipper's profit curves $\left(t_{1}\right.$ varies with $\left.t_{2}=3\right)$

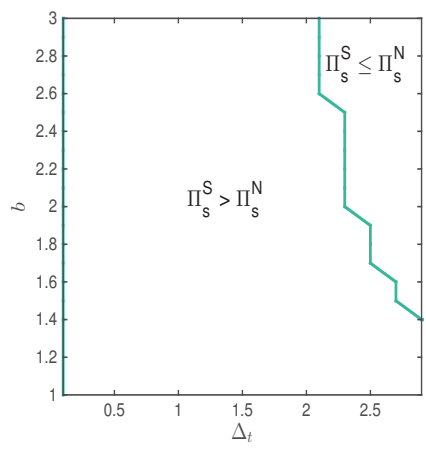

(c) Single sourcing v.s. dual sourcing

Figure 7: Numerical results when $F(\theta)=1-(1-\theta)^{b}$ and $\theta \in[0,1]\left(c_{p}=0.4\right)$

First, we consider a power distribution $F(\theta)=1-(1-\theta)^{b}$ where $\theta \in[0,1]$. This coincides with a uniform distribution when $b=1$, and as $b$ increases, higher-end customers have less demand. ${ }^{18}$ We computed in total 1260 instances in which $b$ varies from 1 to 3 with an increment of $0.1, t_{1}$ varies from 0.1 to 2.9 with an increment of $0.2, c_{p}$ varies from 0.2 to 0.8 with an increment of 0.2 , and other parameters are set as $c_{1}=0.2, c_{2}=0.02, a=10, t_{2}=3, h=0.01 c_{p}$. We did not observe multiple equilibria in any tested instances. Figure 7 reports several representative instances. Figure 7(a) indicates that as demand grows among the low-end customer segments, the equilibrium freight rates drop, a larger portion of shipments shift to the slow carrier, and the two carriers' payoffs decline. This implies that a larger $b$ makes carrier competition more intense under the dual sourcing strategy. Consequently, as $b$ increases, the advantage of single sourcing relative to dual sourcing is weakened and thus single sourcing becomes less favorable (see Figure 7(c)). However, our main results continue to hold when $\theta$ is not uniformly distributed:

\footnotetext{
${ }^{18}$ We thank an anonymous referee for suggesting that we explore this distribution.
} 
Single sourcing can still be superior to dual sourcing in many instances (Figure 7(c)) and the shipper's profit can still be U-shaped in $t_{1}$ (Figure $7(\mathrm{~b})$ ). The U-shaped curve becomes flatter as $b$ increases, because given a very large $b$, most demand belongs to the low end and this leaves little room for quality differentiation, thereby making the competition quite fierce irrespective of the gap between $t_{1}$ and $t_{2}$. Besides the results presented in Figure 7 , we also observed that carrier 2 can be better off as carrier 1 speeds up for any fixed value of $b$, indicating that our main findings from carriers' perspective are robust under more general customer-type distributions.

In addition, we conducted two more sets of numerical experiments, first when $\theta$ follows a uniform distribution with a positive lower limit $\underline{\theta}$, and second a triangular distribution with decreasing density. We found that similar to the rationale discussed above, single sourcing becomes less attractive as $\underline{\theta}$ increases. The additional numerical results are reported in Appendix S2 of the Supplementary Material.

\subsection{Setup Cost}

In the base model, we have ignored the shipper's setup cost for arranging an additional shipment. Suppose now that the shipper incurs an internal setup cost $K$ if an additional carrier is used. Carriers compete in freight rates $r_{i}$ 's, or equivalently, the $w_{i}$ 's in the base model. Intuitively, two carriers are simultaneously used only if the setup cost $K$ can be justified by the value of product differentiation. Given any full variable costs, the shipper's optimal cutoffs are characterized in the following proposition.

Proposition 5. For any given $\left(w_{1}, w_{2}\right)$, the shipper's optimal shipping strategies are given by one of the following cases: (i) if

$$
\begin{array}{r}
w_{1}+2 \sqrt{\bar{\theta} \Delta_{t} K}<w_{2}+\bar{\theta} \Delta_{t}, \\
w_{1}>\gamma w_{2}+2 \sqrt{\gamma \bar{\theta} \Delta_{t} K},
\end{array}
$$

then use both carriers and $\theta_{1}^{*}=\frac{1}{2}\left(\bar{\theta}+\frac{w_{1}-w_{2}}{\Delta_{t}}\right)$ and $\theta_{2}^{*}=\frac{1}{2}\left(\bar{\theta}+\frac{w_{2}}{a-t_{2}}\right)$; (ii) otherwise, exclusively use carrier 1 (resp. carrier 2 ) and $\theta_{1}^{*}=\theta_{2}^{*}=\frac{1}{2}\left(\bar{\theta}+\frac{w_{1}}{a-t_{1}}\right)$ (resp. $\theta_{1}^{*}=\bar{\theta}$ and $\theta_{2}^{*}=\frac{1}{2}\left(\bar{\theta}+\frac{w_{2}}{a-t_{2}}\right)$ ) if $\frac{w_{1}}{\sqrt{a-t_{1}}}-\bar{\theta} \sqrt{a-t_{1}} \leq$ (resp. $>$ ) $\frac{w_{2}}{\sqrt{a-t_{2}}}-\bar{\theta} \sqrt{a-t_{2}}$.

Inequalities (8) and (9) provide the conditions under which dual-mode shipping is optimal in the presence of a setup cost $K$. When $K=0$, inequalities (8) and (9) reduces to the previous conditions (4) and (5) in our base model. The set of $w_{i}$ 's satisfying inequalities (8) and (9) shrinks as $K$ increases, implying that a higher setup cost makes dual-mode shipping less attractive. 
The following proposition shows that the main results regarding the Nash equilibrium in our base model remain valid, but that the condition for dual-mode shipping is adapted to (10).

Proposition 6. Suppose that the shipper incurs a setup cost $K$ for using an additional carrier and adopts a dual-sourcing strategy as in the base model. There is a unique Nash equilibrium in the pricing game between carriers. Moreover, in equilibrium, the shipper uses both carriers with quotations $\left(w_{1}^{N}, w_{2}^{N}\right)$ given by $(7)$ if and only if

$$
(2 \gamma-1) w_{2}^{o}-\bar{\theta} \Delta_{t}+(8 \gamma-2) \sqrt{\frac{K \bar{\theta} \Delta_{t}}{\gamma}}<w_{1}^{o}<\frac{\gamma}{2 \gamma-1} w_{2}^{o}+\frac{2 \gamma}{2 \gamma-1} \bar{\theta} \Delta_{t}-\frac{8 \gamma-2}{2 \gamma-1} \sqrt{K \bar{\theta} \Delta_{t}}
$$

Moreover, dual-mode shipping is a possible equilibrium for some $\left(w_{1}^{o}, w_{2}^{o}\right)$ if and only if $K \leq$ $\frac{\gamma(\gamma-1)\left(\bar{\theta}\left(a-t_{2}\right)-w_{2}^{o}\right)^{2}}{4(2 \gamma+\sqrt{\gamma}-1)^{2} \bar{\theta}\left(a-t_{2}\right)}$.

The shipper's profit function under dual-mode shipping will remain as it was before, with the exception that a constant setup cost is subtracted. Therefore, the effects of $t_{1}$ and $t_{2}$ described in Section 4.3 are intact as long as condition (10) is satisfied. Also, Theorem 6 shows that the shipper may possibly use both carriers in equilibrium given that the setup cost does not exceed a certain threshold. In practice, logistics service providers that specialize in perishable-product cargo often provide door-to-door delivery service ${ }^{19}$. In many cases, then, the setup cost would not be prohibitive. In addition, our analysis in Section 4.4 reveals that even without setup costs, the shipper may be better off with single sourcing instead of dual sourcing because of the cost advantage due to carrier competition. This key insight will not change in the presence of setup costs.

\subsection{Quantity Discounts}

Thus far, we have assumed that carriers use linear pricing. Now, we check the robustness of our results by allowing carriers to compete in nonlinear pricing schemes. Specifically, we assume the discounted freight rate for one unit of shipment by carrier $i$ to be given by a linear form $r_{i}-\beta_{i} v_{i}$ if the shipping volume via carrier $i$ equals $v_{i}$, where $r_{i}$ is the regular rate and $\beta_{i}$ represents the discount factor. This specification is in line with Lee et al. (2015b) in which the authors also studied a pricing problem in the freight transport industry. To rule out unreasonable discount schemes, we assume that the total payment to carrier $i$ (i.e., $\left.\left(r_{i}-\beta_{i} v_{i}\right) v_{i}\right)$ is nondecreasing in $v_{i}$, or equivalently, $r_{i} \geq 2 \beta_{i}$. The game setup remains as before except that each carrier $i$ simultaneously determines $r_{i}$ and $\beta_{i}$ and the shipper optimizes its shipping strategy based on

\footnotetext{
${ }^{19}$ See, for example, http://www.transitfruits-eagle.com/en/door-door-transit and http://www.lynden. com/logistics/seafood.html.
} 
both $\left(r_{i}, \beta_{i}\right)$ 's. As before, we define $w_{i}=r_{i}+h t_{i}+c_{p}$ and assume $w_{i}<\bar{\theta}\left(a-t_{i}\right)$ for all $i$ without loss of generality (otherwise, carrier $i$ will receive no shipments even when it is the only option for the shipper).

The following proposition characterizes the shipper's optimal strategy given any discount schemes where $B(\boldsymbol{\beta})=\bar{\theta}\left(a-t_{2}\right) \beta_{1}+\bar{\theta}\left(a-t_{1}\right) \beta_{2}-\beta_{1} \beta_{2}-\bar{\theta}^{2}\left(a-t_{2}\right)\left(t_{2}-t_{1}\right)$.

Proposition 7. For any given $\left(w_{1}, \beta_{1}\right)$ and $\left(w_{2}, \beta_{2}\right)$, the shipper's optimal shipping strategies are given by one of the following cases: (i) If $B(\boldsymbol{\beta})<0$ and

$$
\begin{array}{r}
w_{1}<w_{2}+\bar{\theta} \Delta_{t}-\left(\gamma-\frac{w_{2}}{\bar{\theta}\left(a-t_{2}\right)}\right) \beta_{2}, \\
w_{1}>\gamma w_{2}+\left(1-\frac{w_{2}}{\bar{\theta}\left(a-t_{2}\right)}\right) \beta_{1},
\end{array}
$$

then using both carriers is optimal and $\theta_{1}^{*}=\theta_{1}^{D}$ and $\theta_{2}^{*}=\theta_{2}^{D}$ where $\theta_{1}^{D}=\frac{\bar{\theta}\left[B(\boldsymbol{\beta})-\bar{\theta}\left(a-t_{2}\right)\left(w_{1}-w_{2}-\beta_{1}\right)+\beta_{2}\left(w_{1}-\beta_{1}\right)\right]}{2 B(\boldsymbol{\beta})}$ and $\theta_{2}^{D}=\frac{\bar{\theta}^{2}\left(a-t_{2}\right)+\bar{\theta} w_{2}-2 \beta_{2} \theta_{1}^{D}}{2\left(\bar{\theta}\left(a-t_{2}\right)-\beta_{2}\right)}$; (ii) otherwise, it is optimal to exclusively use carrier $i$ where $i$ is chosen as $i^{*}=\arg \max _{i=1,2} \frac{\left(w_{i}-\bar{\theta}\left(a-t_{i}\right)\right)^{2}}{4\left(\bar{\theta}\left(a-t_{i}\right)-\beta_{i}\right)}$; moreover, $\theta_{1}^{*}=\theta_{2}^{*}=\theta_{1}^{S}$ if $i^{*}=1$ and $\theta_{1}^{*}=\bar{\theta}$ and $\theta_{2}^{*}=\theta_{2}^{S}$ if $i^{*}=2$, where $\theta_{i}^{S}=\frac{\bar{\theta}\left(\bar{\theta}\left(a-t_{i}\right)-2 \beta_{i}+w_{i}\right)}{2\left(\bar{\theta}\left(a-t_{i}\right)-\beta_{i}\right)}$ for $i=1,2$.

As compared to our base model, the conditions under which dual-mode shipping is optimal become more stringent in the presence of quantity discounts. Note that by assumption $B(\boldsymbol{\beta})$ is increasing in both $\beta_{1}$ and $\beta_{2} \cdot{ }^{20}$ Based on Proposition 7 , given the competitor's discount scheme $\left(w_{-i}, \beta_{-i}\right)$, carrier $i$ 's best response is determined by comparing two possible strategies: (i) share the business with its competitor with a relatively small discount factor $\beta_{i}$ such that $B(\boldsymbol{\beta})<0$ or (ii) win over the entire business by imposing a large enough discount factor $\beta_{i}$. The shipper may thus adopt either single-mode or dual-mode shipping in equilibrium. Propositions C.1 and C.2 in Appendix C provide necessary conditions for either case to be an equilibrium. Based on these conditions, we developed an algorithm to numerically find the dual-mode shipping equilibrium if it exists (see Algorithm 1 in Appendix C).

Intuitively, quantity discounts give each carrier an extra device to compete with each other, which in turn intensifies competition and yields greater cost advantages for the shipper. As reported in Figures 8(a) and 8(b), which plot the profits of both the shipper and the carriers with and without quantity discounts, ${ }^{21}$ quantity discounts make the shipper better off but make

\footnotetext{
$20 \frac{\partial B(\boldsymbol{\beta})}{\partial \beta_{i}}=\bar{\theta}\left(a-t_{-i}\right)-\beta_{-i}>0$, because the assumptions $w_{i}<\bar{\theta}\left(a-t_{i}\right)$ and $r_{i} \geq 2 \beta_{i}$ together imply that $\bar{\theta}\left(a-t_{i}\right)>r_{i} \geq \beta_{i}$ for all $i$.

${ }^{21}$ Parameters used in Figure 8 are $\theta \sim U[0,1], a=10, c_{1}=0.4, c_{2}=0.02, c_{p}=0.1, h-0.01 c_{p}$. In Figure 8(a), $t_{1}$ was varied from 1 to 2.6 with stepsize of 0.1 . Our algorithm generated a unique equilibrium until $t_{1} \leq 2.6$, implying that no dual-mode shipping equilibrium exists for $t_{1} \geq 2.7$ because carrier 2 would be used exclusively. We also tested a few instances with different values of $c_{p}$; the results are similar.
} 


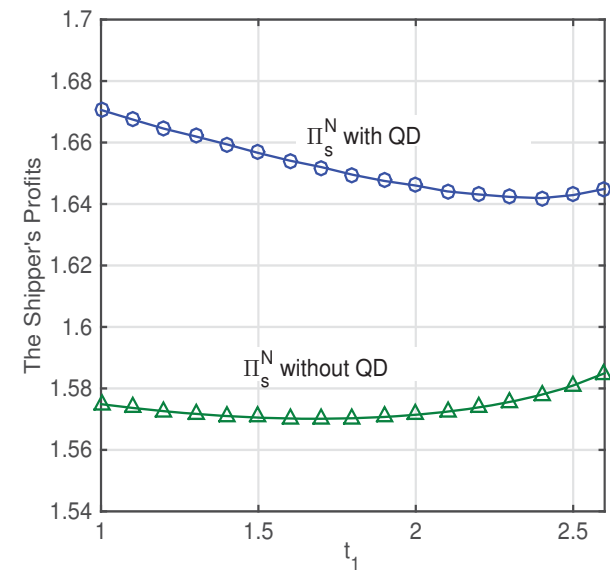

(a) The shipper's profit

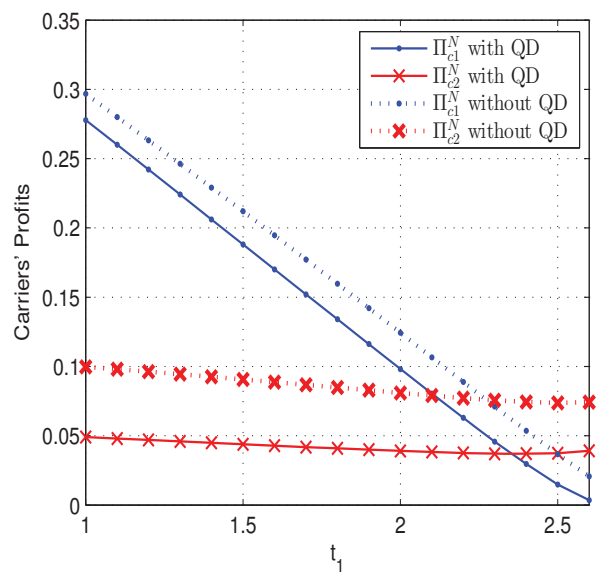

(b) Two carriers' profits

Figure 8: Impact of quantity discounts (QD) on the shipper's and carriers' profits $\left(t_{2}=3\right.$, only dual-mode shipping equilibria plotted)

the carriers worse off, all else being equal. In particular, Figure 8(a) indicates that the shipper's profit curve can still be U-shaped under quantity discounts but that the shape becomes much flatter and more downward sloping. This is because under quantity discounts, the benefit from carrier competition is already substantial even when $t_{1}$ is small.

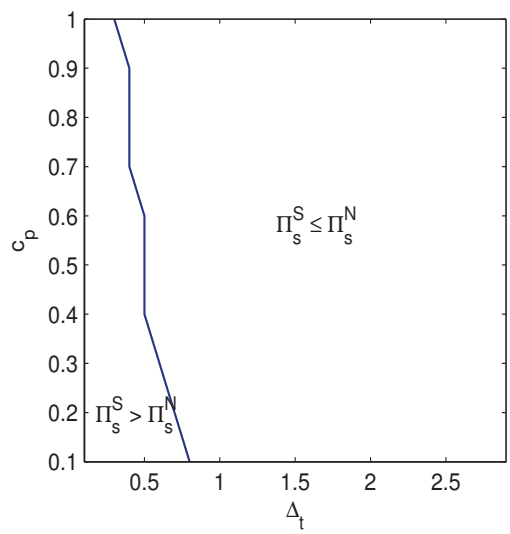

(a) With quantity discounts

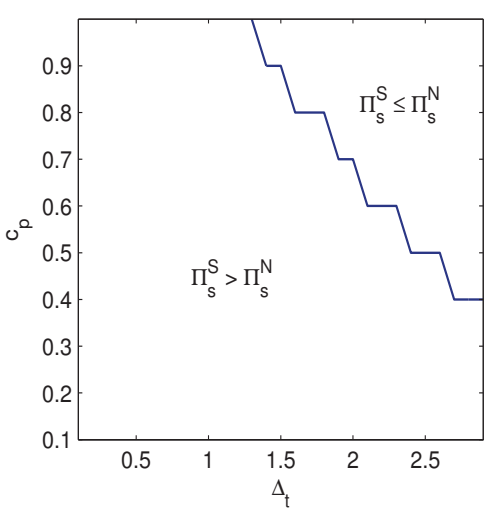

(b) Without quantity discounts

Figure 9: Impact of quantity discounts on the sourcing strategies

One might anticipate that quantity discounts discourage dual sourcing. However, Figure 9 shows that dual sourcing is more favorable under quantity discounts. ${ }^{22}$ Quantity discounts make carrier competition under dual sourcing already quite intense and therefore any additional cost advantage generated by single sourcing may no longer justify the loss of operational advantage from dual sourcing.

\footnotetext{
${ }^{22}$ The Nash equilibrium under single sourcing is characterized in Proposition C.3.
} 


\section{Conclusions}

This paper studies a transportation procurement problem involving a perishable-product shipper, two competing carriers and a destination market consisting of heterogeneous customers. Our analysis provides answers to the research questions raised in the introduction:

- When should a shipper use multiple shipping modes to serve a vertically differentiated market? Given freight rates, the shipper benefits from dual-mode shipping if it can yield a higher profit margin by using the faster service and fulfill the needs of more customers who have less demanding quality preferences by using the slower service. To some extent, this result is consistent with several empirical observations. Being shipped via sea instead of only air freight, Malian mangoes can reach broader market segments in the EU (Sangho et al., 2011, p. 18). By contrast, mango exporters from Peru emphasize the high return of air-freighted mangoes (Passion Fresh, 2013).

- When carrier competition plays a role, what are the implications for the shipper's sourcing strategies and the profits of both the shipper and the carriers? Because of the cost advantages from carrier competition, we find that the shipper's profit can be U-shaped in the gap between the speeds of two carriers, suggesting that the shipper should contract with the carriers with either considerably distinct or very similar services. From the carrier's perspective, our results imply that when a firm is competing with a faster rival, it may be better off strategically by slowing down its service further. Furthermore, while intuition might suggest that restricting shipments to a single carrier is always suboptimal compared to dual-sourcing strategies, we found that this not to be true when carriers compete; rather, single sourcing may be more beneficial to the shipper than dual sourcing because it intensifies carrier competition. However, while dual sourcing permits product differentiation, it can lower the cost advantage from carrier competition (as compared to single sourcing). For this reason, product differentiation, despite receiving strong praises in the revenue management and marketing literature, could potentially hurt the shipper.

We generalized our base model in three ways. First, by showing the log-supermodularity of the carrier game under certain regularity conditions, we numerically verified the robustness of our main results under various customer-type distributions. Second, when the shipper incurs a setup cost for sourcing from an additional carrier, our results for dual-mode shipping remain valid as long as the setup cost does not exceed an upper threshold. Third, allowing carriers to offer quantity discounts instead of only linear freight rates, we found that carrier competition becomes more intense (than under linear freight rates) under the dual-sourcing strategy; consequently, 
the value of single sourcing relative to dual sourcing is weakened under quantity discounts.

Our work has limitations that point to directions for future research. There are other metrics in fruit quality that are not captured in our model. Araújo and Garcia (2016) mentioned that the market can also be segmented for organic and nonorganic mangoes. One could interpret the shipper in our model as a non-organic fruit exporter. In reality, there could be organic fruit exporters competing with nonorganic suppliers for the overall demand. To some extent, this can be captured in our model by introducing a positive outside option for customers. If customers value the organic option equally, the outside option can then be normalized to zero and our model applies. In addition, our model assumes that the product is identical at the time of harvest. In practice, the exporter may export different varieties of mangoes and customers may have preferences among those. Incorporating multiple product varieties prior to shipping would be a valuable topic for future research.

\section{Acknowledgments}

We would like to thank Prof. Hau Lee (the department editor), the associate editor and two anonymous referees for their constructive comments, which helped improve the paper. The work described here was supported by a grant from the Research Grants Council of the HKSAR, China, T32-620/11.

\section{References}

Araújo, J.L.P., J.L.L. Garcia. 2016. A study of the mango market in the european union. Revista Econômica do Nordeste 43(2) 281-296.

Babich, V., A. N. Burnetas, P. H. Ritchken. 2007. Competition and diversification effects in supply chains with supplier default risk. Manufacturing $\&$ Service Operations Management 9(2) 123-146.

Bagnoli, M., T. Bergstrom. 2005. Log-concave probability and its applications. Economic theory 26(2) 445-469.

Bernstein, Fernando, Francis de Véricourt. 2008. Competition for procurement contracts with service guarantees. Operations Research 56(3) 562-575.

Boyd, Stephen, Lieven Vandenberghe. 2004. Convex optimization. Cambridge university press. 
Cachon, Gérard P, Fuqiang Zhang. 2006. Procuring fast delivery: Sole sourcing with information asymmetry. Management Science 52(6) 881-896.

Cachon, Gérard P, Fuqiang Zhang. 2007. Obtaining fast service in a queueing system via performance-based allocation of demand. Management Science 53(3) 408-420.

Calvo, E., V. Martínez-de Albéniz. 2015. Sourcing strategies and supplier incentives for shortlife-cycle goods. Management Science 62(2) 436-455.

CBI. 2016. Exporting mangoes to europe. Available at https://www.cbi.eu/node/1891/pdf. Retrieved on 2017-11-25.

Chen, Y.-J., B. Tomlin, Y. Wang. 2013. Coproduct technologies: product line design and process innovation. Management Science 59(12) 2772-2789.

Cheon, S., C.-Y. Lee, Y. Wang. 2017. Processing time ambiguity and port competitiveness. Production and Operations Management 26(12) 2187-2206.

Correa-López, M. 2007. Price and quantity competition in a differentiated duopoly with upstream suppliers. Journal of Economics 83 Management Strategy 16(2) 469-505.

Desai, P., S. Kekre, S. Radhakrishnan, K. Srinivasan. 2001. Product differentiation and commonality in design: Balancing revenue and cost drivers. Management Science 47(1) 37-51.

Ha, Albert Y, Lode Li, Shu-Ming Ng. 2003. Price and delivery logistics competition in a supply chain. Management Science 49(9) 1139-1153.

Hoen, K.M.R., T. Tan, J.C. Fransoo, G.-J. van Houtum. 2013. Switching transport modes to meet voluntary carbon emission targets. Transportation Science 48(4) 592-608.

Hortiwise. 2013. The Kenyan-Dutch sea freight supply chain for roses. http://edepot. wur.nl/ 313836. Retrieved on 2017-11-30.

Larsen, I K. 2003. Freight transport as value adding activity: A case study of norwegian fish transports. Institute of Transport Economics $\mathbf{6 1 1 0 .}$

Lee, C.-Y., H. L. Lee, J. Zhang. 2015a. The impact of slow ocean steaming on delivery reliability and fuel consumption. Transportation Research Part E: Logistics and Transportation Review 76 176-190.

Lee, C.-Y., C. S. Tang, R. Yin, J. An. 2015b. Fractional price matching policies arising from the ocean freight service industry. Production and Operations Management 24(7) 1118-1134. 
Lim, A., B. Rodrigues, Z. Xu. 2008. Transportation procurement with seasonally varying shipper demand and volume guarantees. Operations Research 56(3) 758-771.

Lu, Tao, Ying-Ju Chen, Brian Tomlin, Yimin Wang. 2018. Selling co-products through a distributor: The impact on product line design. Production and Operations Management Forthcoming.

Lu, Tao, Jan C Fransoo, Chung-Yee Lee. 2017. Carrier portfolio management for shipping seasonal products. Operations Research 65(5) 1250-1266.

Moorthy, K. S. 1984. Market segmentation, self-selection, and product line design. Marketing Science 3(4) 288-307.

Moskin, J. 2004. Sushi fresh from the deep ... the deep freeze. The New York Times http://www . nytimes . com/2004/04/08/nyregion/sushi-fresh-from-the-deep-the-deep-freeze . html. Retrieved on 2017-11-27.

Mussa, M., S. Rosen. 1978. Monopoly and product quality. Journal of Economic theory 18(2) 301-317.

Netessine, S., T. A. Taylor. 2007. Product line design and production technology. Marketing Science 26(1) 101-117.

Notteboom, T. E., B. Vernimmen. 2009. The effect of high fuel costs on liner service configuration in container shipping. Journal of Transport Geography 17(5) 325-337.

Pan, X. A., D. Honhon. 2012. Assortment planning for vertically differentiated products. Production and Operations Management 21(2) 253-275.

Passion Fresh. 2013. Peru: Air-shipped mangoes offer the best business opportunities. Available at http://www.freshplaza.com/article/113363/ Peru-Air-shipped-mangoes-offer-the-best-business-opportunities.

Reuters. 2017. Update 1-norway's seafood exports surged 23 percent to record high in 2016. Available at https://www.reuters.com/article/norway-seafood-export/ update-1-norways-seafood-exports-surged-23-percent-to-record-high-in-2016-idUSL5N1EUOWX.

Sangho, Yéyandé, Patrick Labaste, Christophe Ravry. 2011. Growing Mali's mango exports: Linking farmers to market through innovations in the value chain. The World Bank. Available at http://siteresources.worldbank.org/AFRICAEXT/Resources/ 258643-1271798012256/Mali_Mangoes_Success.pdf. Retrieved on Nov. 24, 2017. 
Sharypova, K., T. van Woensel, J. C. Fransoo. 2012. Coordination and analysis of barge container hinterland networks. Working paper, Eindhoven University of Technology, Netherlands.

Singh, N., X. Vives. 1984. Price and quantity competition in a differentiated duopoly. The RAND Journal of Economics 546-554.

Tanaka, Y. 2001. Profitability of price and quantity strategies in a duopoly with vertical product differentiation. Economic Theory 17(3) 693-700.

Topkis, Donald M. 1998. Supermodularity and Complementarity. Princeton University Press.

Villas-Boas, J. M. 1998. Product line design for a distribution channel. Marketing Science 17(2) 156-169.

Yang, Z., G. Aydin, V. Babich, D. R. Beil. 2012. Using a dual-sourcing option in the presence of asymmetric information about supplier reliability: Competition vs. diversification. Manufacturing \& Service Operations Management 14(2) 202-217.

\section{Appendices}

\section{A Summary of Notation}

\section{B Additional Technical Results of the Base Model}

Proposition B.1. The best response of carrier $i(i=1,2)$ is characterized by a piece-wise linear and increasing function $\hat{w}_{i}\left(w_{-i}\right)$, which is expressed as follows:

$$
\hat{w}_{1}\left(w_{2}\right)= \begin{cases}w_{1}^{o} & \text { if } w_{2}<w_{1}^{o}-\bar{\theta} \Delta_{t} \\ \frac{w_{2}+w_{1}^{o}+\bar{\theta} \Delta_{t}}{2} & \text { if } w_{1}^{o}-\bar{\theta} \Delta_{t} \leq w_{2}<\frac{w_{1}^{o}+\bar{\theta} \Delta_{t}}{2 \gamma-1} \\ \frac{1}{\gamma} w_{2} & \text { if } \frac{w_{1}^{o}+\bar{\theta} \Delta_{t}}{2 \gamma-1} \leq w_{2}<\frac{w_{1}^{o}+\bar{\theta}\left(a-t_{1}\right)}{2 \gamma} \\ \frac{w_{1}^{o}+\bar{\theta}\left(a-t_{1}\right)}{2} & \text { if } w_{2} \geq \frac{w_{1}^{o}+\bar{\theta}\left(a-t_{1}\right)}{2 \gamma}\end{cases}
$$

and

$$
\hat{w}_{2}\left(w_{1}\right)= \begin{cases}w_{2}^{o} & \text { if } w_{1}<\gamma w_{2}^{o} \\ \frac{w_{1}}{2 \gamma}+\frac{w_{2}^{o}}{2} & \text { if } \gamma w_{2}^{o} \leq w_{1}<\frac{\gamma\left(w_{2}^{o}+2 \bar{\theta} \Delta_{t}\right)}{2 \gamma-1} \\ w_{1}-\bar{\theta} \Delta_{t} & \text { if } \frac{\gamma\left(w_{2}^{o}+2 \bar{\theta} \Delta_{t}\right)}{2 \gamma-1} \leq w_{1}<\frac{w_{2}^{o}+\bar{\theta}(2 \gamma-1)\left(a-t_{2}\right)}{2} \\ \frac{w_{2}^{o}+\bar{\theta}\left(a-t_{2}\right)}{2} & \text { if } w_{1} \geq \frac{w_{2}^{o}+\bar{\theta}(2 \gamma-1)\left(a-t_{2}\right)}{2} .\end{cases}
$$

Proposition B.2. Under the single sourcing strategy, the equilibrium is given by one of the following four cases: 
Table 1: Summary of mathematical notation

\section{Notation in the base model}

$c_{p}=$ production $/$ procurement cost

$h=$ inventory holding cost

$\iota=$ interest rate to calculate $h$

$a=$ maximum potential quality of the product

$p_{i}=$ selling price at time $t_{i}$

$\theta=$ customer's marginal utility

$F(\theta)=$ cumulative distribution function of $\theta$

$\bar{\theta}=$ upper limit of $\theta$

$\theta_{i}=$ cutoff point of the shipment via carrier $i$

$c_{i}=$ operating cost of carrier i

$t_{i}=$ transportation time of carrier $i$

$r_{i}=$ freight rate of carrier $i$

$w_{i}=r_{i}+c_{p}+h\left(a-t_{i}\right)$, full variable cost of carrier $i$

$w_{i}^{o}=c_{i}+c_{p}+h\left(a-t_{i}\right)$, min. full variable cost of carrier $i$

$\Pi_{c i}=$ profit of carrier i

$\Pi_{s}=$ profit of the shipper

\section{Thresholds}

$\Omega^{d}$ : set of $\left(w_{1}^{o}, w_{2}^{o}\right)$ for dual-mode shipping equilibria.

$\left[w_{1}^{L}\left(w_{2}^{o}\right), w_{1}^{U}\left(w_{2}^{o}\right)\right]$ : interval of $w_{1}^{o}$ for dual-mode shipping equilibria for any given $w_{2}^{o}$

$\left[\phi\left(w_{2}^{o}\right), \bar{\phi}\left(w_{2}^{o}\right)\right]$ : interval of $w_{1}^{o}$ within which single sourcing is superior to dual sourcing

(i) If $w_{1}^{o} \leq 2 \sqrt{\gamma} w_{2}^{o}+(\gamma-2 \sqrt{\gamma}) \bar{\theta}\left(a-t_{2}\right)$, then $w_{1}^{S}=\frac{w_{1}^{o}+\bar{\theta}\left(a-t_{1}\right)}{2}, \quad w_{2}^{S}=w_{2}^{o}$ and the shipper uses carrier 1 and obtains a profit $\Pi_{s}^{S}=\frac{\left[\bar{\theta}\left(a-t_{1}\right)-w_{1}^{o}\right]^{2}}{16(\bar{\theta}-\underline{\theta})\left(a-t_{1}\right)}$.

(ii) if $2 \sqrt{\gamma} w_{2}^{o}+(\gamma-2 \sqrt{\gamma}) \bar{\theta}\left(a-t_{2}\right)<w_{1}^{o} \leq \sqrt{\gamma} w_{2}^{o}+(\gamma-\sqrt{\gamma}) \bar{\theta}\left(a-t_{2}\right)$, then $w_{1}^{S}=\sqrt{\gamma} w_{2}^{o}+$ $(\gamma-\sqrt{\gamma}) \bar{\theta}\left(a-t_{2}\right), w_{2}^{S}=w_{2}^{o}$ and the shipper uses carrier 1 and obtains a profit $\Pi_{s}^{S}=$ $\frac{\left[\bar{\theta}\left(a-t_{2}\right)-w_{2}^{o}\right]^{2}}{4(\theta-\underline{\theta})\left(a-t_{2}\right)} ;$

(iii) if $\sqrt{\gamma} w_{2}^{o}+(\gamma-\sqrt{\gamma}) \bar{\theta}\left(a-t_{2}\right)<w_{1}^{o} \leq \frac{\sqrt{\gamma}}{2} w_{2}^{o}+\left(\gamma-\frac{1}{2} \sqrt{\gamma}\right) \bar{\theta}\left(a-t_{2}\right)$, then $w_{1}^{S}=w_{1}^{o}$, $w_{2}^{S}=\frac{1}{\sqrt{\gamma}} w_{1}^{o}-(\sqrt{\gamma}-1) \bar{\theta}\left(a-t_{2}\right)$ and the shipper uses carrier 2 and obtains a profit $\Pi_{s}^{S}=\frac{\left[\bar{\theta}\left(a-t_{1}\right)-w_{1}^{o}\right]^{2}}{4(\bar{\theta}-\underline{\theta})\left(a-t_{1}\right)} ;$

(iv) if $w_{1}^{o}>\frac{\sqrt{\gamma}}{2} w_{2}^{o}+\left(\gamma-\frac{\sqrt{\gamma}}{2}\right) \bar{\theta}\left(a-t_{2}\right)$, then $w_{1}^{S}=w_{1}^{o}, w_{2}^{S}=\frac{w_{2}^{o}+\theta\left(a-t_{2}\right)}{2}$ and the shipper uses carrier 2 and obtains a profit $\Pi_{s}^{S}=\frac{\left[\theta\left(a-t_{2}\right)-w_{2}^{o}\right]^{2}}{16(\bar{\theta}-\underline{\theta})\left(a-t_{2}\right)}$.

Proposition B.3. For all $w_{2}^{o} \in\left[w_{1}^{L}\left(w_{2}^{o}\right), w_{1}^{U}\left(w_{2}^{o}\right)\right]$, we have $w_{1}^{L}\left(w_{2}^{o}\right) \leq w_{1}^{p}\left(w_{2}^{o}\right) \leq w_{1}^{U}\left(w_{2}^{o}\right)$, and $\Pi_{s}^{S} \geq \Pi_{s}^{N}$ if $w_{1}^{o}=w_{1}^{p}\left(w_{2}^{o}\right)$ where $w_{1}^{p}\left(w_{2}^{o}\right)=\sqrt{\gamma} w_{2}^{o}+\bar{\theta}\left(a-t_{2}\right)[\gamma-\sqrt{\gamma}]$.

Proposition B.4. For $\left(w_{1}^{o}, w_{2}^{o}\right) \notin \Omega^{d}, \Pi_{s}^{S} \leq \Pi_{s}^{N}$.

Proposition B.5. Suppose $\theta$ follows a general distribution that has an IFR. Given any freight rates under which dual-mode shipping is optimal, the shipper's optimal profit is (i) decreasing 
in $t_{1}, t_{2}, w_{1}, w_{2}$, and (ii) increasing as the distribution of $\theta$ becomes larger in the first-order stochastic sense.

\section{Formulation and Technical Results of the Quantity-Discount Model}

The shipper's problem, given discount schemes $\left(r_{i}, \beta_{i}\right)(i=1,2)$, is adapted to

$$
\max _{0 \leq \theta_{2} \leq \theta_{1} \leq \bar{\theta}} \Pi_{s}(\Theta)=\sum_{i=1}^{2} \theta_{i}\left(t_{i+1}-t_{i}\right) \frac{\bar{\theta}-\theta_{i}}{\bar{\theta}}-\left(w_{1}-\beta_{1} \frac{\bar{\theta}-\theta_{1}}{\bar{\theta}}\right) \frac{\bar{\theta}-\theta_{1}}{\bar{\theta}}-\left(w_{2}-\beta_{2} \frac{\theta_{1}-\theta_{2}}{\bar{\theta}}\right) \frac{\theta_{1}-\theta_{2}}{\bar{\theta}}
$$

Denoting the optimal solution to Problem (C.1) by $\theta_{i}^{*}(\mathbf{w}, \boldsymbol{\beta})$ 's, carrier $i$ solves

$$
\max _{\substack{w_{i} \geq w_{i}^{o} \\ 2 \beta_{i} \leq w_{i}-w_{i}^{o}+c_{i}}} \Pi_{c i}\left(w_{i}, \beta_{i} \mid w_{-i}, \beta_{-i}\right)=\left(w_{i}-w_{i}^{o}-\beta_{i} v_{i}(\mathbf{w}, \boldsymbol{\beta})\right) v_{i}(\mathbf{w}, \boldsymbol{\beta})
$$

where $w_{i}^{o}=c_{i}+h t_{i}+c_{p}, v_{1}(\mathbf{w}, \boldsymbol{\beta})=\frac{\bar{\theta}-\theta_{1}^{*}(\mathbf{w}, \boldsymbol{\beta})}{\bar{\theta}}$ and $v_{2}(\mathbf{w}, \boldsymbol{\beta})=\frac{\theta_{1}^{*}(\mathbf{w}, \boldsymbol{\beta})-\theta_{2}^{*}(\mathbf{w}, \boldsymbol{\beta})}{\bar{\theta}}$.

Proposition C.1. (i) Necessary condition for dual-mode shipping: If the shipper uses both carriers in a Nash equilibrium, the discount schemes $\left(w_{i}^{N}, \beta_{i}^{N}\right)$ in this equilibrium must be a solution to the following system of equations:

$$
\left.\frac{\partial \prod_{c i}\left(w_{i}, \beta_{i} \mid w_{-i}^{N}, \beta_{-i}^{N}\right)}{\partial w_{i}}\right|_{w_{i}=w_{i}^{N}, \beta_{i}=\beta_{i}^{N}}=0, \quad \beta_{i}^{N}=\frac{w_{i}^{N}-w_{i}^{o}+c_{i}}{2}, \text { for } i=1,2 \text { and }-i \neq i .
$$

(ii) Necessary condition for single-mode shipping: Given any fixed $\left(w_{-i}, \beta_{-i}\right)$, if carrier $i$ 's best response is to entice the shipper to exclusively use it, its optimal discount scheme is given by the following optimization problem

$$
\begin{array}{cc}
\max _{w_{i}, \beta_{i}} & \Pi_{c i}\left(w_{i}, \beta_{i} \mid w_{-i}, \beta_{-i}\right)=\left(w_{i}-w_{i}^{o}-\beta_{i}\left(\frac{\bar{\theta}-\theta_{i}^{S}}{\bar{\theta}}\right)\right) \frac{\bar{\theta}-\theta_{i}^{S}}{\bar{\theta}} \\
\text { s.t. } & 2 \beta_{i} \leq w_{i}-w_{i}^{o}+c_{i} \\
\frac{\left(\bar{\theta}\left(a-t_{i}\right)-w_{i}\right)^{2}}{4\left(\bar{\theta}\left(a-t_{i}\right)-\beta_{i}\right)} \geq \frac{\left(\bar{\theta}\left(a-t_{-i}\right)-w_{-i}\right)^{2}}{4\left(\bar{\theta}\left(a-t_{-i}\right)-\beta_{-i}\right)} \\
B\left(\beta_{i}, \beta_{-i}\right) \geq 0
\end{array}
$$

Proposition C.2. The optimal solution to Problem (C.4)-(C.7) must satisfy one of the following properties: (a) $\hat{w}_{i}\left(w_{-i}, \beta_{-i}\right)=w_{i}^{M}$ and $\hat{\beta}_{i}\left(w_{-i}, \beta_{-i}\right)=\beta_{i}^{M}$ where $w_{i}^{M}=\frac{\bar{\theta}^{2}\left(a-t_{i}\right)^{2}+\bar{\theta}\left(a-t_{i}\right) w_{i}^{o}-\beta_{i}^{M} w_{i}^{o}}{2 \bar{\theta}\left(a-t_{i}\right)-\beta_{i}^{M}}$ and $\beta_{i}^{M}=\frac{1}{4}\left(4 \bar{\theta}\left(a-t_{i}\right)+c_{i}-\sqrt{8 \bar{\theta}^{2}\left(a-t_{i}\right)^{2}-8 \bar{\theta}\left(a-t_{i}\right) c_{i}+8 \bar{\theta}\left(a-t_{i}\right) w_{i}^{o}+c_{i}^{2}}\right) ;(b) \frac{\left(\bar{\theta}\left(a-t_{i}\right)-\hat{w}_{i}\left(w_{-i}, \beta_{-i}\right)\right)^{2}}{\bar{\theta}\left(a-t_{i}\right)-\hat{\beta}_{i}\left(w_{-i}, \beta_{-i}\right)}=$ $\frac{\left(\bar{\theta}\left(a-t_{-i}\right)-w_{-i}\right)^{2}}{\bar{\theta}\left(a-t_{-i}\right)-\beta_{-i}} ;$ (c) $B\left(\hat{\beta}_{i}\left(w_{-i}, \beta_{-i}\right), \beta_{-i}\right)=0$. 
Based on the necessary conditions in Propositions C.1 and C.2, we develop the following procedure to compute dual-mode shipping equilibria (if any) in the quantity-discount model. The idea is to first generate all potential equilibria according to the necessary condition in part (i) of Proposition C.1 and then check for each of the potential equilibria if dual-mode shipping is indeed optimal from the shipper's perspective (by Proposition 7) and if neither carrier is better off deviating from the current solution to the one that attracts the shipper to use it exclusively (by part (ii) of Proposition C.1). As a limitation, we note that Algorithm 1 finds dual-mode shipping equilibria, if any, but it does not rule out the possibility that there might be other single-mode shipping equilibria.

Algorithm 1 (Finding Nash equilibria for dual-mode shipping). Let $\mathcal{S}$ be an empty set.

Step 1. Obtain all of the solutions to equations (C.3), denoted by $\left(w_{1}^{D, 1}, \beta_{1}^{D, 1}, w_{2}^{D, 1}, \beta_{2}^{D, 1}\right),\left(w_{1}^{D, 2}, \beta_{1}^{D, 2}, w_{2}^{D, 2}, \beta_{2}^{D, 2}\right)$, $\ldots,\left(w_{1}^{D, M}, \beta_{1}^{D, M}, w_{2}^{D, M}, \beta_{2}^{D, M}\right)$.

Step 2. For each $m=1,2, \ldots, M$, if $\left(w_{1}^{D, m}, \beta_{1}^{D, m}, w_{2}^{D, m}, \beta_{2}^{D, m}\right)$ satisfies $B\left(\boldsymbol{\beta}^{D, m}\right)<0$ and inequalities (11) and (12), let $\mathcal{S}:=\mathcal{S} \cup\left\{\left(w_{1}^{D, m}, \beta_{1}^{D, m}, w_{2}^{D, m}, \beta_{2}^{D, m}\right)\right\}$.

Step 3. For each element $\left(w_{1}^{D, m^{\prime}}, \beta_{1}^{D, m^{\prime}}, w_{2}^{D, m^{\prime}}, \beta_{2}^{D, m^{\prime}}\right)$ in $\mathcal{S}$ and each $i=1,2$ and $-i \neq i$, check the following: Given $\left(w_{-i}^{D, m^{\prime}}, \beta_{-i}^{D, m^{\prime}}\right)$, does the optimal solution to Problem (C.4)-(C.7) give carrier $i$ a higher profit than $\left(w_{i}^{D, m^{\prime}}, \beta_{i}^{D, m^{\prime}}\right)$ ? If yes, remove $\left(w_{-i}^{D, m^{\prime}}, \beta_{-i}^{D, m^{\prime}}\right)$ from $\mathcal{S}$.

Step 4. Output the set $\mathcal{S}$.

Under the single-sourcing strategy, the game reaches a Nash equilibrium until one of the carriers cannot further adjust the discount scheme and ends up with a zero profit. This leads to the following proposition.

Proposition C.3. Under the single sourcing strategy, carrier $i$ will be selected if and only if $\frac{\left(\bar{\theta}\left(a-t_{i}\right)-w_{i}^{l i m}\right)^{2}}{4\left(\bar{\theta}\left(a-t_{i}\right)-\beta_{i}^{l i m}\right)} \geq \frac{\left(\bar{\theta}\left(a-t_{-i}\right)-w_{-i}^{l i m}\right)^{2}}{4\left(\bar{\theta}\left(a-t_{-i}\right)-\beta_{-i}^{l i m}\right)}$ where

$$
w_{i}^{l i m}=\frac{1}{2}\left(3 \bar{\theta}\left(a-t_{i}\right)+3 w_{i}^{o}-c_{i}-\sqrt{\left.\left(3 \bar{\theta}\left(a-t_{i}\right)+w_{i}^{o}\right)^{2}-10 c_{i} \bar{\theta}\left(a-t_{i}\right)+c_{i}^{2}+2 c_{i} w_{i}^{o}\right)}\right)
$$

and $\beta_{i}^{\text {lim }}=\frac{w_{i}^{\text {lim }}-w_{i}^{o}+c_{i}}{2}$ for $i=1,2$. Moreover, in equilibrium carrier $i$ 's quotation $\left(w_{i}^{S}, \beta_{i}^{S}\right)$ satisfies the following: (i) If $\frac{\left(\bar{\theta}\left(a-t_{i}\right)-w_{i}^{M}\right)^{2}}{4\left(\bar{\theta}\left(a-t_{i}\right)-\beta_{i}^{M}\right)} \geq \frac{\left(\bar{\theta}\left(a-t_{-i}\right)-w_{-i}^{l i m}\right)^{2}}{4\left(\bar{\theta}\left(a-t_{-i}\right)-\beta_{-i}^{l i m}\right)},\left(w_{i}^{S}, \beta_{i}^{S}\right)=\left(w_{i}^{M}, \beta_{i}^{M}\right)$; (ii) otherwise, $\bar{\theta}\left(a-t_{i}\right)-w_{i}^{S}=\sqrt{\frac{\bar{\theta}\left(a-t_{i}\right)-\beta_{i}^{S}}{\bar{\theta}\left(a-t_{-i}\right)-\beta_{-i}^{l i m}}}\left(\bar{\theta}\left(a-t_{-i}\right)-w_{-i}^{l i m}\right)$. 